\title{
LA LENGUA ZAPOTECA Y SU PROCESO DE REVITALIZACION, SIERRA JUAREZ, OAXACA, MÉXICO
}

\author{
Arturo Ruiz López ${ }^{1}$
}

\section{RESUMEN}

En este artículo se abordan los factores socioculturales que están incidiendo para la revitalización de la lengua zapoteca en la Sierra Juárez, Oaxaca, México. Estos factores están incidiendo para que se dé un cambio paulatino en términos de actitud hacia la lengua originaria, en este caso la lengua zapoteca. Esto ha dado lugar a una resistencia lingüística frente al desplazamiento lingüístico a partir extensión del español en diferentes espacios comunicativos. Se aborda también la manera en cómo la lengua zapoteca está recuperando algunas funciones comunicativas en algunos espacios (escuela, radio, espacios públicos, iglesia etc.), dando lugar a un proceso de revitalización de la misma. Así mismo se tienen las opiniones de los padres de familia sobre la importancia y la función de la lengua originaria y del español a nivel familiar y comunitario, en donde se observa una visión clara de la función de cada una de estas lenguas por parte de los usuarios. Hay resaltar que es un cambio que se da desde las comunidades, hace falta un cambio de actitud sociolingüística de la sociedad en general respecto a las lenguas originarias. Otro aspecto que se aborda es el papel que juega la escuela en este proceso de revitalización, lo que ésta hace y lo que opinan los padres de familia en cuanto al uso de la lengua originaria en el aula y la alfabetización en esta lengua en contraste con el español.

PALABRAS CLAVES: Bilingüismo. Educación. Comunicación. Desplazamiento. Lengua originaria.

\section{ABSTRACT}

This article addresses the sociocultural factors that are influencing the revitalization of the Zapotec language in the Sierra Juárez, Oaxaca, Mexico. These factors are influencing a gradual change in terms of attitude towards the original language, in this case

1 Profesor del Tiempo Completo del IISUABJO - Universidade Autónoma Benito Juárez de Oaxaca. Cidade Oaxaca, Estado de Oaxaca, México. E-mail: rarturol@hotmail.com. 
the Zapotec language. This has given rise to a linguistic resistance against the linguistic displacement from the extension of Spanish in different communicative spaces. It also addresses the way in which the Zapotec language is recovering some communicative functions in some spaces (school, radio, public spaces, church, etc.), giving rise to a process of revitalization of it. The opinions of the parents on the importance and function of the native language and Spanish at the family and community level are also taken into account, where a clear vision of the function of each of these languages is observed by the users. It should be noted that it is a change that occurs from the communities, it requires a change of sociolinguistic attitude of society in general with respect to the original languages. Another aspect that is addressed is the role played by the school in this process of revitalization, what it does and what parents think about the use of the original language in the classroom and literacy in this language in contrast to the Spanish.

KEYWORDS: Bilingualism. Education. Communication. Displacement. Native language.

\section{Introducción}

En este apartado se hará una descripción de los factores socioculturales que consideramos han influido para detener el desplazamiento paulatino de la lengua originaria por el español. A partir de diversos trabajos de investigación y de trabajo de campo realizado, en un periodo amplio de manera intermitente, en algunas comunidades de la región de la Sierra Juárez, Oaxaca, México, nos hemos percatado que se están generando algunas acciones que están deteniendo este proceso de desplazamiento.

Si bien es cierto que la escuela es una instancia que ha contribuido desde los años 20 del siglo pasado en este proceso, vemos actualmente que desde la escuela se están haciendo algunos esfuerzos que están contribuyendo a la revitalización de la lengua originaria. Pero también, consideramos que no es suficiente lo que se hace desde la escuela como se verá en la presente exposición. Hay otros factores socioculturales que puede tener mayor repercusión o en su caso, nos atrevemos a decir que en su conjunto pueden dar lugar a que las lenguas originarias logren revitalizarse y ocupen un 
papel importante en la vida cotidiana y en el proceso escolar como consecuencia.

Encontramos en los testimonios ideas y posiciones relevantes respecto al uso y funciones de una y otra lengua, dependiendo del espacio y del contexto es cómo valoran la importancia de cada una. En el mismo sentido hay opiniones contrastantes respecto a la enseñanza de estas lenguas en la escuela. Sin embargo, hace falta desde nuestra perspectiva un mayor conocimiento, por parte de los padres de familia, autoridades comunitarias y docentes, de la importancia de la lengua materna (en este caso de la lengua zapoteca) en el proceso enseñanza aprendizaje.

\section{Factores socioculturales que han favorecido la lengua zapoteca en la Sierra Juárez, Oaxaca, México}

En este apartado daremos cuenta de la forma en que consideramos se ha detenido el desplazamiento de la lengua zapoteca en la Sierra Juárez de Oaxaca. A pesar de la tendencia hacia el monolingüismo en español que existe en esta región, se presenta un proceso importante en cuanto a la revaloración de la lengua indígena, en donde han intervenido varios factores; entre los que tenemos: a) la escuela, b) la formación de los docentes indígenas, c) el alfabeto práctico para la escritura de la lengua zapoteca, d) la producción de textos, e) la radio, f) actividades académico/culturales, g) la música, h) la migración. Si bien es cierto que se trata de un proceso que se da "desde dentro", hace falta conocer en qué medida el "otro", la población no indígena, está cambiando su actitud hacia las lenguas indígenas y hacia los hablantes de estas lenguas.

\subsection{La escuela y el papel que ha jugado en la revaloración de la lengua indígena}

Precisamente la escuela es una de las instancias que ha favorecido el bilingüismo, lo que ha dado lugar a un paulatino desplazamiento de la lengua zapoteca por el castellano en las situaciones comunicativas públicas de mayor importancia. Todo esto es parte de un proceso general de cambio social, donde tienen gran peso los medios de comunicación, los servicios públicos (la 
escuela) o privados con los que cuentan las comunidades, así como la población emigrante.

Uno de los problemas relacionados con lo anterior tiene que ver con la cultura escolar, de manera específica, el uso de la lengua indígena en el aula, debido a las diferentes actitudes de los padres de familia y los maestros bilingües respecto a su uso o no como lengua de instrucción.

Son principalmente los padres de familia, quienes abogan porque se hable el español en la escuela, ya que consideran que representa prestigio y movilidad social. Lo que se deduce de esta posición es que los padres de familia tratan de evitar un problema económico y/o social a futuro para sus hijos, pero no reflexionan sobre los problemas de aprendizaje que implica esta situación de conflicto lingüístico, ya que afecta en los alumnos en los aspectos pedagógico, psicológico o sociocultural en los alumnos.

Esto era lo que teníamos hasta los años ochenta, en donde la escuela jugó un papel muy importante en cuanto al desplazamiento de la lengua indígena en los diferentes espacios comunicativos. Sin embargo, es oportuno señalar que hoy día se está dando un cambio paulatino en cuanto a la actitud de los padres de familia, maestros y autoridades comunitarias respecto al uso de la lengua indígena en el proceso escolar, dado que cada vez hay una mayor aceptación del uso de la lengua indígena como lengua de instrucción. Aunque la escuela no será, la única instancia que detendrá este proceso como lo veremos más adelante.

La escuela comienza de una manera incipiente a utilizar la lengua indígena, ha desarrollar contenidos étnicos, a producir literatura indígena; en fin, inicia acciones tendientes a la revitalización del zapoteco; aunque finalmente la escuela no es y no va ser la única instancia en donde se pueda lograr este cambio lingüístico y cultural. ${ }^{2}$ Sin duda es importante el papel que está jugando la escuela en la región, y de manera particular en las comunidades en donde se tiene el sistema de educación indígena.

2 Se apuesta fuertemente, por ejemplo, a un proceso de alfabetización en lengua indígena, como una forma importante para revitalizar esta lengua. 


\subsection{La formación de los docentes para la educación indígena}

Otro elemento que está presente en el cambio de actitud hacia la lengua indígena es la formación académica de los docentes indígenas (Cf. Mena y Ruiz, 1997). Si bien es cierto, esto no es determinante, como no lo es ninguno de los otros factores, sólo en su conjunto han influido y podrán seguir impactando en este proceso. El hecho de que existan docentes formados académicamente no significa que existan cambios sustanciales en el campo educativo, ni en cuanto al uso de la lengua oririgiaria como lengua de instrucción. Esto lo hemos observado en la región, hay maestros que han estudiado en la Universidad Pedagógica Nacional (UPN), pero no se observa ningún cambio en su práctica docente relacionado con el uso de la lengua indígena en el proceso escolar o la recuperación de contenidos comunitarios, ni un cambio de la actitud ante la diversidad lingüística y cultural. Por el contrario, también hemos conocido maestros que sin tener formación universitaria están desarrollando actividades a favor de la lengua y cultura indígena dentro de su práctica docente. Deducimos entonces que uno de los problemas principales que padece la educación indígena se deriva de la formación de los docentes que prestan sus servicios en el Sistema de Educación Indígena.

Después de la creación del Sistema Nacional de Promotores Culturales y Maestros Bilingües en 1963, se realizaron varios intentos para profesionalizar a los docentes indígenas. En Oaxaca, siguiendo la idea integracionista se crea el Instituto de Investigación e Integración Social del Estado de Oaxaca (IIISEO), el cual tuvo vigencia de 1968 a 1976, mientras que a nivel nacional se establecieron algunos programas de licenciatura: en el Centro de Investigaciones y Estudios Superiores en Antropología Social (CIESAS), el Programa de Etnolingüística (1979-1982 y 19831987); en el Centro de Investigación e Integración Social (CIIS), el Programa de Licenciatura en Ciencias Sociales (1981-83, 19841987). Sin embargo, debido a problemas políticos, se le retiró el presupuesto al CIIS y su segunda generación fue retomada por el CIESAS. Más recientemente la Unidad Ajusco de la Universidad Pedagógica Nacional, ofertó en la Ciudad de México la Licenciatura en Educación Indígena (LEI), a partir de 1982, en modalidad escolarizada.

Estos programas impartidos en la modalidad escolarizada, sirvieron para profesionalizar a los maestros de educación indígena 
en servicio, quienes estudiaban gracias a una beca-comisión. ${ }^{3}$ Pero a partir de 1990 se establece la modalidad semiescolarizada con el programa de Licenciatura en Educación Preescolar y Educación Primaria para el Medio Indígena (LEPyLEPMI, Plan 90), en 35 unidades distribuidas en 23 estados de la República Mexicana. En cada uno de estos programas escolarizados se propuso como objetivo formar cuadros docentes especializados en aspectos técnico-pedagógicos. Para el caso de Oaxaca, la mayoría de sus egresados ocupan puestos administrativos dentro de la estructura del Departamento de Educación Indígena en el Estado, hoy Dirección de Educación Indígena. Sólo algunos están en la Escuela Normal Bilingüe e Intercultural de Oaxaca (ENBIO), y otros más en Centro de Desarrollo de Lenguas Indígenas de Oaxaca (CEDELIO). Únicamente los egresados de la licenciatura semi-escolarizada de la UPN, retornan a sus comunidades de trabajo, que de hecho nunca abandonan, dado que permanecen en éstas durante sus periodos de estudio, y es aquí en donde pudiera suponerse que modifican sus actitudes hacia la lengua y cultura indígena en general y sus prácticas docentes en particular.

De los programas de nivel Superior que se han implementado para profesionalizar al personal docente de educación indígena, actualmente sólo están en activo la LEI (Unidad Ajusco-UPN) y la LEPyLEPMI, en sus modalidades escolarizada y semiescolarizada, respectivamente; en el año 2000 se creó la Escuela Normal Bilingüe e intercultural, programa escolarizado que está captando a estudiantes indígenas del estado de Oaxaca. A nivel de Posgrado tenemos el Programa de Maestría en Etnolingüística (CIESASMéxico), que capta no necesariamente a docentes indígenas, pero sí a hablantes de alguna lengua indígena, y el Programa de Maestría en Sociolingüística de la Educación Básica y Bilingüe (UPN-Unidad 20-a Oaxaca).

Respecto a la LEPyEPMI, en el estado de Oaxaca funciona en tres Unidades: en la ciudad de Oaxaca, en Tuxtepec y una más en Ciudad Ixtepec. La Unidad 20-a Oaxaca, actualmente tiene cinco subsedes de las siete que llegó a tener; en todas estas

3 Estas becas comisión consistieron en mantener el sueldo de maestros para que pudieran realizar sus estudios de licenciatura en los lugares sede de cada programa. 
subsedes (Tlaxiaco, Huautla de Jiménez, Huajuapan, Cacahuatepec, Jamiltepec) funciona la LEPyEPMI.

Una pregunta interesante respecto a los docentes que se han formado de 1990 a la fecha sería: ¿Cuál es el impacto educativo de los maestros que egresan de las LEPyLEPMI en el estado? Es un tema que requiere una investigación profunda, sobre todo para conocer la repercusión del trabajo de estos maestros en la educación indígena, ¿cómo están modificando sus prácticas pedagógicas a partir de elementos teóricos y metodológicos que reciben?, el tratamiento que le dan a la lengua y a la cultura indígenas, la forma como abordan los contenidos comunitarios y extracomunitarios, etc. Algunos comentarios en relación a su trabajo son los siguientes:

Yo creo que nada más algunos están interesados en poner en práctica lo que están aprendiendo, porque ahi mismo hay gente que va, pero por el papel, no van porque quieran hacer algo verdaderamente por la gente. Porque, yo les he dicho a los maestros que trabajen pensando en los niños, no pensando en el cumplimiento del director o el supervisor, ;no! Sino qué clase de gente formar... Entonces hay quienes van a la Universidad porque hay exigencia de presentar un documento para asegurar la plaza, y terminan, ¿qué pueden hacer?, no hay interés. Yo lo veo, porque hay gente que nos llega, nos da tristeza que vienen de escuelas bilingües y traen boleta para cuarto, quinto o tercero, y niños que no saben leer, es una lástima. A mí, me da mucho coraje, quisiera denunciarlos, echan a perder a los niños, de la zona Chinanteca, por ejemplo. Y dicen: "es que los maestros se están dos tres días y se van". La mayoría de los niños llegan mal, y qué hacemos, ni modos de regresarlos (HD, Zoochina, 2003).

Ellos dicen, y sí, echan rollo, cuando hacemos cursos, pero es dificil observar cómo trabajan. No me ha tocado trabajar con ellos, con los que me ha tocado, algunos maestros sí trabajan, otros no. Lázaro de por sí lo ha llevado a cabo (el uso de la lengua indígena), si se mete un poco, ha hecho poesía en zapoteco; pero los demás, ni porque sean o tengan otro poquito más de estudio... no sé, no les gusta, no entiendo si la 
preparación influye o no. Le han entrado los maestros más grandes, pero los más chavos no le entran ( $\mathrm{SH}$, Zoochina, 2003).

Aquí la percepción es que hay maestros, sobre todo los de más edad, que sin tener una preparación universitaria, muestran interés y empeño en la enseñanza de la lengua indígena, ya sea mediante la alfabetización, del uso de esta lengua en el proceso enseñanza aprendizaje. Mientras que los jóvenes, aunque tengan más preparación, no se empeñan en la utilización de la lengua indígena.

\subsection{El alfabeto práctico para la lengua zapoteca}

La construcción de un alfabeto para la escritura de la lengua zapoteca de la Sierra Norte, al igual que el de otras muchas lenguas indígenas del estado de Oaxaca, ha pasado por diferentes procesos. Existen desde propuestas individuales, hasta propuestas respaldadas por alguna institución, o por alguna organización local regional. Una de las instituciones que ha trabajado en este tema ha sido el Instituto Lingüístico de Verano (ILV) ${ }^{4}$. Las comunidades de la Sierra Juárez no son ajenas a los trabajos realizados por el ILV, el cual, al conocer la diversidad lingüística de las comunidades, sus variantes dialectales, procedieron a crear alfabetos para cada comunidad en

4 El Instituto lingüístico de Verano (ILV) nace en México en 1936, con el beneplácito del Presidente Lázaro Cárdenas, quien brinda apoyo a su fundador William C. Towsend. El ILV es una asociación civil que tiene por objetivo el estudio científico de la las lenguas autóctonas de país. Elabora y publica en distintos idiomas diccionarios y gramáticas, materiales para promover la lectoescritura, cuentos tradicionales y traducciones de textos bíblicos. Su influencia en las comunidades indígenas a través de las sectas religiosas ha sido bastante cuestionada por organizaciones, comunidades e investigadores (Colegio de Etnólogos y Antropólogos Sociales de México), lo que dio lugar a su expulsión del país en 1982, por su política de penetración cultural con la excusa de realizar trabajos lingüísticos. En 1985, el titular de la arquidiócesis mexicana de Chihuahua, arzobispo Dizán Vázquez, aseveró que "la Agencia Central de Inteligencia (CIA) utiliza sectas religiosas como instrumento de penetración ideológica y transculturización" y agregó que, entre ellas, se encuentra el ILV, al que tildó de "ultraconservador, fanáticamente anticomunista y aliado del militarismo estadounidense". Actualmente el ILV sigue trabajando en México con otra denominación y con otros "objetivos". 
donde se establecieron ${ }^{5}$. Otros alfabetos que se construyeron fueron: el de la Universidad Nacional Autónoma de México (UNAM), del lingüista Juan José Rendón; el de la Dirección Genera de Educación Indígena (DGEI); el de la Asamblea de Autoridades Zapotecas y Chinantecas de laSierra (AZACHIS), en1981; el de la Dirección General de Culturas Populares, en 1984, entre otros alfabetos que fueron conocidos nada más al algunos pequeños grupos de personas, y que no fueron consensados; por lo tanto, no era posible leer los textos que se escribían con estos alfabetos.

Es hasta 1983 cuando surgen las Secundarias Bilingües ${ }^{6}$ y con ellas la necesidad de integrar una asignatura a la que se denominó "Lengua adicional", en este caso "Lengua indígena", como parte del programa de estudios. Sin embargo, ésta se convirtió en un problema que tuvieron que comenzar a resolver los directivos de estas escuelas con un proyecto de unificación de los alfabetos, un alfabeto que fuera consensado y pudiera ser utilizado por un sector más amplio de profesores y alumnos. Entonces hubo la necesidad de buscar el apoyo de otras instituciones, organizaciones o personas, para trabajar en torno a un solo alfabeto. Una de las personas que participaron activamente en este proceso y que además, fue directivo del Centro de Integración Social No 8 de la comunidad de Zoogocho, opinó al respecto:

...tuvimos un primer acercamiento con los de Culturas Populares, donde dijimos: "bueno, intercambiemos ideas, es necesario unificar el alfabeto”. Entonces convocamos a las demás organizaciones que estaban trabajando con el alfabeto, y tuvimos la primera reunión en Zoogocho. Empezamos a discutir, cada quien comenzó a exponer su alfabeto, los motivos, los cuales fueron los fundamentos para dar cierta grafía o ciertos sonidos, cada quien dio su argumento... y era difícil que en una reunión sacáramos el producto ... y así seguimos teniendo reuniones. A medida que ibamos avanzando se iba agregando más gente para participar. Fue cuando se vio la necesidad de formar

5 Algunos alfabetos que se elaboraron fueron de las variantes dialectales de: Zoogocho, Yatzachi el Bajo, San Pedro Cajones, entre otros.

6 Estas secundarias no tuvieron continuidad y posteriormente fueron absorbidas por el Sistema de Secundarias Técnicas dentro del sistema educativo estatal. 
una Coordinadora, así se llamó: Coordinadora de la lectoescritura. Y empezamos a trabajar, a dejarnos tareas, escribir palabras; y en otra reunión, a exponerlas como las habíamos escrito, y todo eso... (JL, Yatzachi el Bajo, 2002).

El proceso desarrollado fue muy importante, ya que participaron personas con diferentes niveles de escolaridad, desde personas con educación primaria hasta profesionistas, cuya participación fue sobre todo a partir de su interés por la construcción de un alfabeto práctico que sirviera a todos para escribir la lengua zapoteca. Otro aspecto rescatable en este proceso fue la participación de los ancianos, autoridades comunitarias y padres de familia, así como la de maestros de educación indígena de diversas comunidades indígenas, apoyos con los cuales se logró conformar un alfabeto práctico zapoteco.

Para darle seguimiento a este trabajo se estableció una Coordinadora para la lecto-escritura de la lengua $S a$ en la Sierra Norte. Esta representación fue la responsable de realizar diferentes reuniones de trabajo a lo largo de 16 años. En la última de esas reuniones, efectuada en la comunidad La Josefina, Ixtlán de Juárez, se acordó incluir en el alfabeto una sexta vocal, en función de las características de la variante dialectal del Sector Rincón: /ë/.

Cabe decir que en la actualidad un considerable número de maestros utiliza este alfabeto para la producción de textos, así como para alfabetizar a sus alumnos de Educación Primaria. Con este hecho se cumple con los compromisos contraídos con la Coordinadora, según lo manifiesta el mismo profesor entrevistado:

... pasaron como dos años hasta que quedó un alfabeto... hicimos un compromiso de que este alfabeto lo usaríamos todos, claro que hubo quienes se opusieron porque ya tenían libros, porque ellos ya tenían trabajo hecho, los que no teníamos nada, no teníamos nada que perder, porque estábamos empezando; sin embargo, después de todo aceptaron y empezaron también a usar el alfabeto. La primera institución con la que empezamos a emplear este alfabeto fue Culturas Populares, porque ella sí estaba trabajando sobre la lengua y fuer la primera en usar el alfabeto (JL. Yatzachi el Bajo, 2002). 
Otra institución que utilizó este alfabeto fue el Instituto Nacional para la Educación de los Adultos (INEA), con la participación de algunos integrantes de la Coordinadora, previa autorización de todos los miembros de la misma. Esos materiales recuperan las variantes dialectales de las comunidades del Sector Zoogocho, Cajones y Villa Alta, con una metodología de enseñanza que combina el aprendizaje del alfabeto a partir de las grafías que tienen mayor frecuencia de uso y por campo semántico. Desafortunadamente Culturas Populares no le dio los créditos por esto a la Coordinadora, lo que generó descontento, pues fue parte de los compromisos contraídos para la realización de estos textos (SEPDGEI, 1993). Esta acción generó nuevamente desconfianza ante las instituciones gubernamentales. Es necesario aclarar que el grupo que constituyó la Coordinadora fue un grupo autogestivo, que no tuvo en ningún momento apoyo institucional, ni lo buscó, fue parte de su política de trabajo: construir un alfabeto a partir de un interés propio, que surgiera desde dentro de las comunidades, y que no fuera una imposición.

Una pregunta que está presente en todo este proceso es: ¿Qué pasa con las variantes dialectales? En un primer momento fue un problema enorme, dado que los maestros lo tomaban como un "buen pretexto" para no alfabetizar en lengua indígena, argumentando que los textos no eran acordes con las variantes dialectales de los lugares trabajaban. Afortunadamente este problema se está superando, y hoy día ya no se ve como un problema o como un obstáculo. Lo que se está haciendo es adaptar los materiales a las variantes dialectales de cada comunidad. Lo que demuestra que más que un problema era una actitud negativa, una barrera que se imponía el propio maestro para no utilizar el texto, para no llevar a la práctica la alfabetización en lengua indígena.

Si este proceso se hubiera dado de otra manera, quizá ahora nos estaríamos refiriendo a textos específicos para cada una de las variantes ${ }^{7}$, o inclusive para cada comunidad, pues la diversidad lingüística en la Sierra Norte es demasiado compleja: de una comunidad a comunidad la diversidad dialectal es notoria,

7 En esta región hablamos de cuatro grandes variantes dialectales de la lengua zapoteca: sector rincón, sector Villa Alta, sector Ixtlán y sector Zoogocho-Cajonos. 
a nivel fonético, semántico o léxico. ${ }^{8}$ Si no se hubiese hecho así, se tornaría casi imposible escribir en la lengua zapoteca, además de dar lugar a la segmentación de la lengua en lugar de conseguir su estandarización. Por otra parte, si bien es cierto que existen maestros que todavía tienen una actitud negativa hacia el uso de la lengua indígena, también es cierto que este cambio es paulatino y deben transcurrir varios años más para tener un panorama distinto. Hace falta un proceso de concientización de los sujetos involucrados en este proceso, sólo una parte de este trabajo se realizó en la década de los noventa del siglo pasado: se efectuaron diferentes seminarios, talleres para la enseñanza del alfabeto a los maestros de Educación Indígena, con el apoyo de los integrantes de la Mesa Técnica de la Jefatura de Zonas de Supervisión de Guelatao de Juárez; 9 También, entre 1994-95, se logró el nombramiento de una persona en cada zona escolar para darle seguimiento a los trabajos de lecto-escritura en lengua indígena. Esto favoreció enormemente el trabajo de socialización del alfabeto práctico para la escritura de la lengua zapoteca, así como su seguimiento en cada una de las escuelas. Uno de las personas entrevistadas, al respecto manifestó lo siguiente:

Del 84 para acá, podemos decir que en el magisterio bilingüe (de la región) hay $80 \%$ que sabe leer y escribir, porque anteriormente nadie sabia, y si escribían, cada quien escribía a su manera, pero ahorita sí están alfabetizados en zapoteco y sí se están haciendo los trabajos. El Internado es una de las instituciones en donde más trabajan eso, ha desarrollado poesía, cuadros cómicos, con trabajo de los mismos niños; y hasta ahi veo el avance... pero, no sé yo la Dependencia, la DGEI, no sé si le esté dando seguimiento, mucho depende de arriba que siga incentivando a los maestros para que lo sigan desarrollando. (JL, Yatzachi el Bajo, 2002).

8 Por ejemplo, a nivel semántico, en Tabaá dicen: Chego, rápido, en Zoochina sees; Chaliá, patio y chhi'o, Tabaá y Zoochina respectivamente, son comunidades que están a una hora de distancia en autobús.

9 A nivel regional existe una Jefatura de Zonas de Supervisión en Guelatao de Juárez, que tiene bajo su administración siete zonas escolares ubicadas en los distritos de Ixtlán y Villa Alta. Esta tiene un equipo de apoyo académico y otro de apoyo administrativo. El autor de este texto participó en los trabajos de capacitación para el aprendizaje de la lecto-escritura en zapoteco de esta Jefatura. 
Y agrega, a partir de su experiencia y el contacto que tiene con los maestros:

... pero, yo pienso que se necesita más apoyo todavía, para que puedan desarrollar más los maestros todo, pero veo que ya no hay resistencia como en un principio, que no aceptan, que no entienden, que no se puede, eso ya no, ya no existe en los maestros, cualquier maestro ya platica sobre su experiencia, ya platica que ya lo ha hecho, que si le funciona, pero el problema es que terminan la primaria los niños $y$ ahi se quedan, eso es lo malo, entonces no hay continuidad. (JL, Yatzachi el bajo, 2002).

Es evidente que en el nivel de Educación Primaria se está retomando la lengua indígena, pero, ¿qué pasará en los otros niveles educativos? Es otra de las preocupaciones que se tienen, la Secundaria Bilingüe desapareció, pero hoy día se están instalando escuelas de Educación Media Superior (bachilleratos) en la región, y habrá la necesidad de profesionistas que sepan leer y escribir en lengua indígena, ya que dentro de su cuadro de materia está la de "Lengua Indígena".

\subsection{Producción de textos}

Otro elemento que es necesario mencionar es la producción de textos, revistas, literatura indígena, propuestas metodológicas, etc. ${ }^{10}$ Estos materiales han sido generados tomando como base el alfabeto práctico de la lengua zapoteca. Trabajos realizados de manera individual o de manera colectiva, con apoyo institucional o

10 Algunos de estos textos son: en Literatura: Molina Cruz, Mario, El arco iris atrapado, CID-Sierra, Oaxaca, 1995; Molina Cruz, Mario (Coord.), Yi’ kube (Fuego nuevo). Taller de lengua y tradición zapoteca de Yalalag, Oaxaca, México, 1998; Castellanos M., Javier, Yell chhia lhen xtilla. Zanhe xbab Sa, Segunda edición, Oaxaca, México, 1999; revista: CID-Sierra. GWZIO. Revista Cultural, Zapoteca, Mixe, Chinanteco, Oaxaca, México, enero-junio 1996; propuestas metodológicas: INEA, Bzoj dilla xhon, (Libro y Cuaderno de ejercicios), INEA, México, 1991; Muñoz, Héctor, et al., Bene Xhon, (Guía para alfabetización bilingüe y libro de trabajo), libros de Educación Primaria, primero, segundo y tercer ciclo, CID-Sierra, Oaxaca, México, 1995. 
sin apoyo, pero con la intención de demostrar que la lengua indígena tiene todas las posibilidades de escribirse.

En la primera mitad de los años setenta, la DGE a nivel central trató de elaborar textos para la alfabetización en lengua indígena. Pero estos materiales no fueron aceptados en las escuelas, porque el alfabeto utilizado fue hecho por un pequeño grupo de maestros, asesorados por lingüistas de la DGEI, y porque no hubo una participación directa de los maestros de campo en la elaboración de éste. Estos textos no impactaron en las escuelas, hubo un rechazo porque los maestros no conocían el alfabeto, no estaban alfabetizados en lengua zapoteca, por lo que decidieron no aplicarlos. Es hasta los años ochenta cuando se revierte este proceso y se empiezan a elaborar otros textos, principalmente libros de narrativa y revistas ${ }^{11}$, a partir de un alfabeto consensado y aceptado por un sector de población de la Sierra Juárez.

Posteriormente lo retomó la Dirección General de Educación Indígena, fue cuando agarró más auge el alfabeto, porque entonces se difundió en toda la Sierra, entonces la DGEI, dijo: "Sabemos que ya hay un alfabeto, queremos que nombren a las personas que vengan a elaborar los libros para los niños"; y ahi se nombró al maestro Fidencio. Se fueron tres personas de aqui a hacer el trabajo en México, ahi estuvieron haciendo los libros, primer ciclo, segundo ciclo, tercer ciclo. Ahorita ignoro si mandaron a hacer más libros, pero se sacaron con trabajos de los maestros, con trabajos de los niños, se hicieron talleres en diferentes escuelas, los niños empezaron a hacer sus producciones, en esos libros aparecen las producciones de los niños... (JL, Yatzachi el Bajo, 2002).

La producción de textos desde las comunidades ha dado mejores resultados porque participan los sujetos involucrados en este proceso. Esto ha sido posible gracias a que ahora se tiene un alfabeto práctico para la escritura del zapoteco. Actualmente existen diversos textos en zapoteco; entre éstos los libros para el primer,

11 Se editó la revista GUZIO, que publica literatura indígena y diversos temas relacionados con la Sierra Juárez tendientes a demostrar la riqueza de la lengua indígena zapoteca. 
segundo y tercer ciclo de Educación Primaria, literatura indígena, materiales didácticos de apoyo, etcétera.

Una estrategia interesante ha sido recuperar los escritos de los propios alumnos para la estructuración de los libros de texto. Esto ha sido muy motivante para los alumnos y los profesores, porque sus esfuerzos materializado en estos textos. En ese mismo sentido, también se incluyen los textos generados en los seminarios que se desarrollan con los propios maestros que se ven involucrados en este proceso.

\subsection{La radio bilingüe como un espacio para la reivindicación de las lenguas indígenas}

En el rubro del rescate de la lengua indígena también podemos mencionar a la radio. En la Sierra Norte existe una emisora de radio que ha sido muy importante en términos de difusión de la cultura indígena. Esta radiodifusora se conoce como "Radio Guelatao", que inició sus actividades el 21 de marzo de 1990. Uno de los objetivos de esta radio es fomentar el rescate y el fortalecimiento de las culturas, principalmente de tres los grupos étnicos localizados en la Sierra Norte de Oaxaca; la mixe, la zapoteca y la chinanteca. Un objetivo más de esta emisora es "coadyuvar al mejoramiento de las comunidades en términos de comunicación, orientación y desarrollo".

De los dos objetivos anteriores se desprende un objetivo adicional: "Contribuir al fortalecimiento de las lenguas, costumbre y otros medios de participación ciudadana"12. En este sentido la radio ha influido en la población indígena, a través de sus transmisiones en las tres lenguas indígenas que se hablan en esta región: zapoteco, chinanteco y mixe. La transmisión radiofónica es variada: música regional, música clásica, cuentos, leyendas, relatos históricos, noticias locales, regionales, nacionales e internacionales, orientaciones jurídicas, etcétera.

Esta radiodifusora es muy aceptada en la región principalmente debido a su programación diversa y porque transmite en las tres lenguas originarias. Sin embargo, nuestro principal entrevistado nos mencionó lo siguiente:

12 Información proporcionada por uno de los locutores de Radio Guelatao. 
Es тиy poco lo que hace porque todo el programa es en español, el ochenta por ciento es en español, lo único que sacan son spots, nada más, "escucha tu radio en el número tanto"... y cantos de algunas comunidades: Pero no se ve el avance, tiene años que repiten lo mismo, una palabrita la repiten tres veces y es todo, no hay más. Una vez escuché una conversación (en zapoteco) de un viejito con su nieto, el abuelito estaba enseñándole el zapoteco al niño y repetían dos, tres palabras, pero hasta ahí nada más. Hay en ciertas horas, algunos programitas. Lo que pasa es que a esa hora no tienen tiempo de escuchar, están trabajando, y en las noches cuando realmente se puede escuchar, no hay programa. A las seis de la tarde ya para su programa y es la hora que llega la gente del campo. Solamente las amas de casa, escuchan... (JL, Yatzachi el Bajo, 2002).

Nuestro informante menciona que hacen falta más programas en lengua indígena, y reconoce que sí se invita a la gente para que participe en las transmisiones. Ha sido un espacio importante, existen horarios para la lengua originaria, así como reflexiones sobre la lengua y la cultura; algunos locutores hacen su transmisión en las lenguas mencionadas, lo que da lugar a la proyección de la lengua. Otro de nuestros entrevistados tiene otra opinión de la importancia que tenido la radio en este proceso de revaloración de la lengua indígena: " ...no nos quita tiempo, no hay que sentarse para "verlo" como la tele, se puede estar trabajando y escudando..."; y a la vez reconoce que existe la necesidad de que los docentes tengan un papel más activo en el proceso de producción radiofónica: “ $S i$, ...a nivel Jefatura han nombrado a un maestro para que participe en la programación, pero no funciona, nadie demuestra interés, porque sí nos pueden dar un espacio (HD, Zoochina, 2002). Un entrevistado más menciona al respecto: "Yo, no sé por qué los maestros no le han entrado, yo creo que podrían implementar un programa para radio, pero también ellos como que no se dan a basto, porque tienen que preparar sus clases, materiales, que reuniones, que paros, todo eso”. (JL, Yatzachi el Bajo). 


\subsection{La música y la producción literaria en el proceso de revaloración de la lengua zapoteca}

La música, cantos, cuentos, literatura indígena, etcétera, son otros elementos que están presentes en el proceso que hemos señalado. Algo que parecía imposible para algunos, pero factible para otros, es la actual producción de cantos, rondas y cuentos en lengua indígena. Inclusive en algunas comunidades se han producido canciones populares en lengua indígena ${ }^{13}$, acompañándose de bandas filarmónicas. Este fenómeno tuvo una repercusión muy importante en la región, ya que esta música era escuchada en todas las comunidades, ya sea a través de los altavoces o a través del radio; tanto niños, como jóvenes y adultos cantaban estas canciones que trascendieron las fronteras por los emigrantes de la región las pedían. Posteriormente, lo retomaron otras personas, así como otras comunidades. Es el caso de Santo domingo Yojovi, en donde los integrantes de la banda Filarmónica de la comunidad interpretan canciones en zapoteco.

Por otra parte, algunos maestros han generado sus propias poesías, cantos y rondas para utilizarlas en el proceso escolar. Es el caso del maestro de Yovego, quien con su grupo de niños de educación primaria y la banda filarmónica de su comunidad, hicieron una grabación de cantos y rondas infantiles en lengua zapoteca. Para los escépticos, los que decían que la lengua indígena solo tenía sentido para la oralidad, y en consecuencia priorizaban el aprendizaje del español, estas acciones les demostraron que sí era posible usar la lengua indígena para diferentes funciones comunicativas. P e r o, ¿la difusión de estos materiales y su uso en las comunidades o en las escuelas, cuál es? Aquí es donde habría que revisar hasta dónde realmente se han convertido en un factor que está contribuyendo en la revaloración de la lengua indígena.

Fue evidente el impacto que tuvieron las canciones indígenas con banda de música de viento, que hoy día han perdido vigencia, ha faltado continuidad. Ahora se escuchan, tanto estas canciones como las canciones infantiles en lengua zapoteca, de manera aislada. Las personas reconoce su importancia, pero también aceptan que hace

13 Con el acompañamiento de bandas filarmónicas en algunas comunidades se cantan canciones populares. 
falta mucho trabajo por realizar, como se puede leer en la siguiente cita:

Hay que saber ser sensible hacia lo que le gusta a la gente y de esa manera poder entrarle, ¿no? Bueno, si les gustan las canciones, vamos a seguir motivando para seguir haciendo canciones de ese tipo, o lo que más les guste, las canciones les gustaron y todo mundo quería una grabación de esas, porque se oía bonito; y lo entendiamos, a lo mejor es acercarse hacia qué quiere la gente.

Algunos maestros lo aplican (canciones, rondas), algunos, pero no todos. Que yo sepa ninguna escuela lo lleva... pues yo, cuántos años estuve en Tabaá, cuatro, nunca, alguna vez algún maestro retomaba eso, poesías, zapoteco-español, de ahí, nada... Ese día del curso lo cantaron (un canto infantil en zapoteco). Es que si se puede, son los cantitos que hay que recuperar, se puede emplear el zapoteco, los niños aprenden, pero no todos lo hacen... se van con lo más fácil, el español (SH, Zoochina, 2003).

A pesar de las circunstancias, concluimos que ha sido muy relevante la función que han tenido estas acciones para la socialización de la lengua indígena y la recuperación que hacen de su lengua materna las personas.

\subsection{El uso de la lengua indígena en encuentros académicos y socioculturales}

Un aspecto más en donde el docente de educación indígena ha intervenido para la revitalización de la lengua zapoteca es en la organización de encuentros académicos o culturales. Estos consisten en reuniones en torno a la poesía, cantos, leyendas, monólogos, comedias, etc., en donde participan niños de educación primaria. En estas actividades también participan las autoridades municipales y educativas de la región en calidad de evaluadores y/o organizadores. Dichos encuentros son interesantes dado que se observa el uso que puede tener la lengua originaria en una actividad concreta, como 
también su funcionalidad en una actividad académica. Lo que se demuestra es la capacidad creativa de los niños a partir de su lengua materna, y la habilidad que han adquirido para la escritura de esta lengua zapoteca. La participación de los maestros, autoridades comunitarias y padres de familia, estimula el interés de los niños en esa actividad, y esto de alguna forma contribuye a un cambio de actitud hacia la lengua indígena, a partir de que se conoce más sobre el uso y la funcionalidad que ésta puede tener. Uno de nuestros entrevistados que ha participado como jurado en estos encuentros narra su experiencia de la siguiente manera:

Yo lo único que veo son los trabajos que presentan, pero de ahí, no lo he visto con los niños de forma directa (el uso de la lengua indígena)... el concurso (en lengua zapoteca) que hubo en Solaga. ahi hubo un concurso de niños, y sí sucedió algo curioso: primero nos llamaron como jurados, y ahi ya traían los lineamientos de cómo se iba calificar y dijeron... En verdad fue sorprendente porque los niños, en esa ocasión hicieron un trabajo formidable, ahi un niño de Betaza hizo un trabajo excelente, su letra no era muy clara pero (se) entendía lo que estaba escribiendo. Porque leyeron su trabajo, ya no fue un trabajo que llevaran de su escuela, sino lo hicieron allá en el salón, en el momento, cada quien escribió sobre cuentos, animales, a ese niño le tocó escribir sobre su comunidad.... Él escribió la problemática que vive su comunidad... (JL, Yatzachi el Bajo, 2002).

Lo anterior es una muestra de lo que es posible hacer cuando se tiene el "interés de trabajar", como dicen los propios maestros. Esta frase lleva mucho significado, debido a que implica no sólo tener el conocimiento sobre el campo de trabajo o la formación académica, sino también el deseo de realizar tareas académicas pertinentes para los niños, dedicar el tiempo necesario para desarrollar estrategias de trabajo, en fin, la entrega en la labor docente. De aquí surgen nuevas estrategias y percepciones de trabajo para seguir impulsando esta actividad; por ejemplo, nos dicen:

...se han hecho exposiciones (en zapoteco), pero no toda gente pasa a leerlo y (aunque)... pasen a leerlo, 
... no todos le ponen atención; entonces, aparte de que se va a exponer se va leer, también se van a hacer cuadernillos para repartir, porque hay gente que está alfabetizada pero no tiene donde leer, el problema es producir. (HD, Zoochina, 2003).

Otra actividad relacionada con el uso y revitalización de la lengua indígena ha sido la organización de encuentros recreativos: de deportes, danza, bailes regionales, actos cómicos, etc. Es el caso de los eventos culturales en donde se observa la creatividad de las personas involucradas en este proceso. Respecto a las obras cómicas nos comentan lo siguiente:

... ya había visto una obra de teatro de Melitón... lo hace en zapoteco y sí está interesante y los niños hablan en zapoteco... son buenos actores los chamacos en zapoteco, la gente como entiende el zapoteco, se ríe, pues también como le buscaba algunos chistes por ahí, así como iban actuando, la gente se reía (SH, Zoochina, 2003).

Lo hasta aquí referido es una evidencia clara de las diferentes actividades que se han realizado para demostrar las funciones de la lengua indígena, además de reconocer toda la riqueza que encierra la lengua indígena en términos del significado y la comprensión que de ella tienen los propios hablantes.

\subsection{La población emigrante y su influencia en la revaloración de la lengua indígena}

Otro factor que consideramos debe estar presente en este análisis es el fenómeno migratorio, pues pareciera ser que con ésta el desplazamiento de la lengua indígena se acelerara; sin embargo, no es así, al menos no ocurre esto en la región de referencia. En el caso de la Sierra Norte, la migración está jugando un papel muy importante en el proceso de revitalización de la lengua zapoteca. No sólo los emigrantes locales/temporales tienen una actitud positiva hacia la lengua indígena, sino también aquellos que han cruzado la frontera o aquellos emigrantes con residencia prolongada en los lugares de destino (Los Angeles California, EEUU, básicamente). Inclusive se tiene conocimiento de personas que aprenden la lengua 
indígena al llegar a estos lugares. Otras personas más, aprenden el inglés y el zapoteco como primeras lenguas y el español como una tercera lengua. Por ello es importante considerar a esta población en este proceso.

Como podemos ver hay una serie de factores que están interviniendo en este proceso de revitalización y cambio de actitud hacia la lengua indígena. No es sólo a través de la escuela como vamos a poder lograr una educación indígena intercultural, debemos de tener en cuenta otros elementos, porque la escuela por sí misma no lo va a conseguir, al menos en nuestro contexto.

¿Cómo se manifiesta en la práctica esto que acabamos de mencionar? En el siguiente apartado vamos a considerar algunos espacios comunicativos en donde la lengua indígena tiene presencia $\mathrm{y}$ sus funciones comunicativas.

\subsection{Espacios y funciones comunicativas de la lengua indígena}

Como ya se ha referido, la lengua zapoteca, una de las lenguas indígenas que se habla en la Sierra Norte, Oaxaca, tiende a revitalizarse. En otro momento, en términos generales, hemos hablado de un proceso de desplazamiento de la lengua indígena por el español, pero para el caso particular del zapoteco de la Sierra Juárez, no podemos afirmarlo, por el contrario, lo que observamos es que se está generando un proceso que permite que esta lengua recupere espacios y funciones comunicativas que en otro momento eran exclusivos del español. Este proceso, si bien es cierto es notable, tendrá que pasar mucho tiempo para que pueda verse con mayor claridad o que pueda tener una presencia más amplia (véase cuadro 1). 
Cuadro 1 - Espacios y funciones comunicativas recuperados por la lengua indígena, 1995.

\begin{tabular}{|c|c|}
\hline ESPA & FUNCIONES \\
\hline 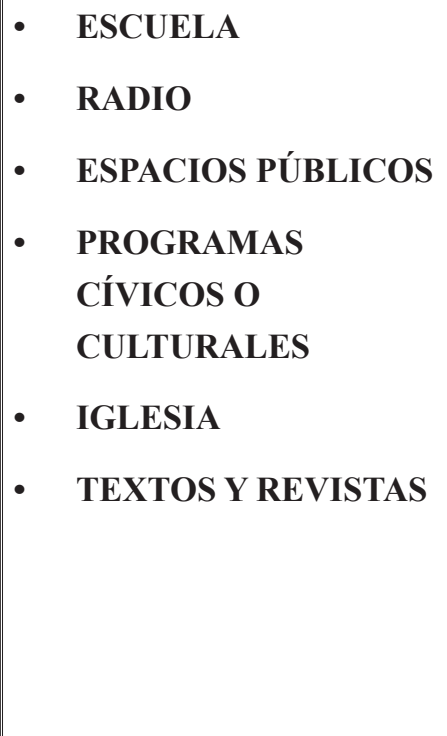 & $\begin{array}{ll}\text { - } & \text { DESARROLLO DE CONTENIDOS } \\
\text { EDUCATIVOS Y/O “LENGUA } \\
\text { PUENTE” } \\
\text { - INFORMACION A TRAVÉS DE LA } \\
\text { RADIO } \\
\text { - CANTOS, POESÍAS, RONDAS } \\
\text { - CANCIONES POPULARES } \\
\text { - SERMONES } \\
\text { - INFORMACIÓN / CONSULTA EN } \\
\text { LA CLÍNICA O MUNICIPIO } \\
\text { DISCURSOS EN PROGRAMAS } \\
\text { CÍVICOS }\end{array}$ \\
\hline
\end{tabular}

Fuente: Trabajo de campo en diferentes periodos en comunidades de la Sierra Juárez, 1995-1999.

En el cuadro anterior podemos observar los espacios comunicativos en donde la lengua indígena está teniendo presencia. En el contexto escolar, la cultura indígena está presente, y empieza a utilizarse para desarrollar contenidos educativos, en algunas ocasiones se emplea como lengua puente (Cf. Muñoz, 1987), como lengua para acceder al español.

Los espacios públicos, en el municipio, en el centro de salud, en la escuela, se usa la lengua indígena sin ninguna restricción. De igual forma tenemos que en la iglesia esta lengua se hace presente, por ejemplo en los "sermones", lo que da lugar a un mayor entendimiento de lo que se dice.

En los programas cívicos, anteriormente se empleaba el español para decir el discurso alusivo, no obstante hoy en día, en esos espacios se empieza de manera sutil a hablar el zapoteco. Una de las reflexiones importantes al respecto es que las lenguas indígenas pueden perdurar no necesariamente a partir de su escritura, sino a 
partir de su uso en diferentes situaciones comunicativas. En este sentido se hace necesario crear conciencia en los sujetos, de tal suerte que se haga uso de la lengua indígena en las reuniones comunitarias, en los tequios (trabajo colectivo), en la relación intra e interfamiliar, en las comunidades en donde el español es utilizado como lengua de interacción. Otro de nuestros entrevistados, que forma parte del cabildo municipal de su localidad expresó lo siguiente:

Pero ahora la gente de aquí de mi pueblo, como ya estoy acá muchos ya me hablan zapoteco ahora, cuando recién regresé me hablaban puro español, pero ahora hasta con los muchachos con quienes no hablaba yo (zapoteco) y ahora que estamos en el municipio al hablar con el Presidente y con los otros regidores que hablan zapoteco, en una reunión tenemos que hablar en zapoteco, en ese momento es cuando ya nos dirigimos en zapoteco con el otro y con el secretario que es más joven (MC, Solaga, 1999).

\section{La lengua indígena en el ámbito familiar-comunitario y en el aula}

\subsection{La lengua indígena y su perspectiva}

En la actualidad, la gran mayoría de la población indígena en el estado de Oaxaca se caracteriza por tener algún grado de bilingüismo (desde un nivel incipiente hasta un bilingüismo coordinado), esto como resultado del contacto con el mundo hispanohablante, ya sea a través de las instituciones públicas o privadas, los servicios, los medios masivos de comunicación, o la migración. Pero, habría que destacar la función que ha tenido la escuela en este proceso, en donde impera la premisa de que quien aprende la lengua dominante tiene mayores éxitos académicos, y en consecuencia mayores posibilidades de movilidad social, hecho por cierto bastante cuestionado en la actualidad. Aunado a esto tenemos las presiones de los padres de familia, quienes influenciados por la ideología dominante, piden que se les enseñe a sus hijos la lengua de "prestigio" (el español), debido a las expectativas ya señaladas. 
Sin embargo, en varias comunidades de la región, a nivel familiar la lengua de mayor uso es la lengua indígena, es la lengua de interacción cotidiana, es la que aprenden la mayoría de los niños, es la que utilizan para comunicarse con los padres, con los abuelos, con los vecinos. Esto es evidente y así lo manifestaron la mayoría de los entrevistados, sobre todo en las comunidades como Yojovi, Yahuio, Guiloxi y Yaganiza. Desde luego que en algunas familias de estas comunidades hay padres que hablan fluidamente el español y hacen todo lo posible por enseñar esta lengua a sus hijos; otros padres, quienes poseen un español incipiente no logran los mismos resultados. En el caso de Solaga, la situación es un tanto diferente, es una comunidad con un índice de bilingüismo más alto; por lo tanto, hay más familias que emplean el español en las interacciones familiares. A pesar de esto, se presentan diferentes situaciones comunicativas en estas comunidades, como los siguientes ejemplos:

... Sí, les corrijo porque como les enseño puro español y su mamá también les habla puro español, y entonces ellas fallan pues porque no saben muy bien hablar, entonces muchas cosas les fallan. Pero ya al salir de la escuela y jugar con sus compañeritos ya les enseñan, pero no pueden pronunciarlo muy bien porque están acostumbradas a que les hablamos puro zapoteco. Yo les corrijo y les digo, esto es, ... esto se dice así, esto se llama así, tal parte se llama así (en español) (DM, Yojovi, 1999).

Pues casi la mayoría está hablando puro zapoteco, como cuatro o cinco casas donde les hablan a sus hijos puro español, pero los niños son los que sí llegan platicando y no olvidan el zapoteco, pero sus padres y madres les hablan español, como cuatro casas están acostumbrados a hablar puro español (OA, Yaganiza, 2000).

Otro aspecto que merece mencionarse es el hecho de que hay familias en donde uno de los padres es monolingüe en español, o habla una lengua indígena diferente a la de la comunidad, entonces la familia tiene la necesidad de hablar el español como lengua de interacción, de comunicación. Aquellos padres que han vivido en 
la ciudad y regresan a vivir en sus comunidades, consideran una ventaja que sus hijos puedan ser bilingües.

... pues ahorita mi hija que tengo acá, es una nada más, porque las otras nacieron en la Ciudad de México. Yo radiqué un tiempo en la Ciudad de México, estuve once años allá, entonces, ya de ahi nos venimos porque mis padres quisieron que llegáramos acá... entonces ya trajimos a dos niñas, pues ellas ya hablaban español, pues, para hablarles zapoteco, pues ellas no entendian, entonces nosotros les seguimos hablando español. La que nació aquí es la que sí está hablando muy bien el zapoteco y español, ahora está en quinto año. Entiende muy bien el español y el zapoteco también, ya lo está escribiendo (DM, Yojovi, 1999).

A nivel comunitario esta situación es más diversa, depende del lugar en donde se esté o con quién se dialogue; allí los espacios comunicativos influyen de alguna manera la lengua que se ha de utilizar. En la tiendas, en la calle, en la casa municipal, o entre vecinos, la lengua más utilizada es el zapoteco, nada más se habla español cuando la interacción es con alguien ajeno a la comunidad o con personas que trabajan en las instituciones públicas. Normalmente se habla en español con los maestros, por ejemplo. También se escuchan cambios de códigos o la mezcla del zapoteco y el español, además de préstamos, aunque esto último, como se dijo, no es bien visto. Uno de nuestros entrevistados al respecto comentó lo siguiente:

Por ejemplo, yo he escuchado del secre (secretario) que dice: "cherha autoridad municipal", entonces, este, "autoridad municipal" o sea es español, lo que está hablando y a la vez zapoteco, pues está hablando las dos cosas, porque autoridad municipal tiene su nombre, ¿no?, en zapoteco y no lo dijo en zapoteco... (DM Yojovi, 1999).

Lo anterior es muy frecuente sobre todo al anunciar por los altavoces de la comunidad, es aquí donde es posible darse cuenta de esta situación, que si bien algunas personas consideran que se trata de una forma "elegante" de hablar, otras la rechazan, porque 
consideran que deteriora el habla y apelan por una manera correcta de hablar la lengua zapoteca, sin préstamos y sin mezclas.

...el que vive aquí dice: hay que hablar puro zapoteco, no revuelvan el español, como el secretario de acá de Tabaá... se oye cerca el aparato (altavoz) de Tabaá cuando hacen un anuncio. Ahí revuelven el zapoteco, casi una mitad de zapoteco y la mitad de español hablan cuando "hablan zapoteco". (DM, Yojovi, 1999).

Este modo de hablar el zapoteco, con préstamos del español, también se observa en los espacios escolares, debido al proceso de castellanización incipiente que se inicia desde la casa, con padres que no dominan esta lengua. Esta situación provoca que se deje de hablar "correctamente" la lengua indígena, al recurrir a los préstamos, a pesar de que los equivalentes de estas palabras sí existen en el léxico cotidiano de los hablantes en zapoteco. Una de nuestras entrevistadas, desde su experiencia áulica nos comentó:

...ya hay muchos préstamos, demasiados, se nos hace más fácil. La gente también como que los toman, como podría decir, como para demostrar que sí dominan el español. Eso lo escucho mucho en Tavehua cuando voy, ocupan mucho los préstamos, porque sí existen en nuestra lengua muchas de las palabras; al menos con los niños allá en el CIS cuando vamos a hacer algún trabajito y empiezan a platicar en zapoteco les digo: si van a hablar zapoteco, hablen zapoteco; pero es que no existe, dicen; cómo no va existir, sí existe, hay que hacer el esfuerzo y hay que preguntarles a los papás, a los abuelos, ellos lo sabrán y, si no, pues hay que retomarlo de los que sí lo saben y sí lo tiene (HD, Zoochina, 2003).

Otra pregunta frecuente en los usuarios de la lengua originaria es: ¿Qué ocurre con los maestros o funcionarios que plantean una educación indígena bilingüe o con aquellas personas que reivindican la lengua indígena? En este aspecto también encontramos diversidad de comportamientos, distintas maneras de reproducción de la lengua indígena. Aquellos maestros o funcionarios que sí les enseñan a sus hijos a hablar la lengua indígena, que son la minoría y los que 
no enseñan la lengua indígena; esto último es lo más común, y la siguiente cita lo demuestra con mucha precisión:

En el campo de la SEP, por ejemplo, si usted entrevistara a una supervisora de educación indigena, o llegara casualmente a su domicilio, se daría cuenta que a su familia le habla en español. Un maestro de educación indígena, si va usted a su casa, y que tenga hijos, se va a dar cuenta que todos hablan español. Hay un amigo maestro, es escritor, cantautor en zapoteco, que a sus hijos les habla en español, sus hijos no pueden hablar zapoteco. Son casos que yo he visto no, ... (EL, Yojovi, 1999).

Como se puede observar, existen diversas actitudes respecto a la lengua indígena y dependiendo de las situaciones y su función específica, se recurrirá a ella o no. Así podemos observar en la Casa Municipal, en la clínica, en las tiendas, es evidente el cambio de código: en las pláticas, en las peticiones, en las preguntas, se usan las dos lenguas indistintamente, sin mayores problemas ni prejuicios.

En la Sierra Juárez existen escuelas de educación indígena y escuelas de educación formal. Estas últimas funcionaban en los años setenta y ochenta con maestros hispanohablantes procedentes de otros estados de la república mexicana. No se autorizaba la contratación de muchos maestros por escuela, por tanto había grupos multigrado; además había mucho ausentismo de los docentes debido a la lejanía de las comunidades, combinado con el horario de trabajo, solo se laboraba en el horario de matutino (un solo turno). En tanto el sistema de educación indígena planteaba proyectos extracomunitarios durante los días laborables, incluyendo los fines de semana, y dotaba a sus escuelas de suficientes profesores hablantes de la lengua indígena y con una presencia permanente en la comunidad para atender a los alumnos con horario de doble turno. ${ }^{14}$

Por este motivo, muchas comunidades optaron por cambiar de sistema educativo, pasaron al modelo de educación indígena, para que los niños fueran mejor atendidos y no hubiera tanta repetición de grado, como ocurría al ser atendidos por los maestros hispanohablantes,

14 La permanencia de los maestros en la comunidad hoy día, solo es para cubrir sus 4 o 5 horas de trabajo al día, en algunas escuelas con horario continuo, y sin trabajos extras. 
debido al uso exclusivo del español en el proceso enseñanza aprendizaje, al menos ese era el supuesto. Además de contar con una educación en donde a los niños se les ayudara a desarrollar la lengua indígena, así como a leer y a escribirla, en paralelo al aprendizaje correcto del español. La siguiente cita nos resume de alguna forma lo que se espera de esta educación:

En aquel entonces aquel muchachito que hablara español en la escuela, todos sus demás compañeritos se burlaban de él, le decían "ba chhun bigolhen" (él presumes mucho)... los niños forzosamente tenían que hablar zapoteco para no ser burlados... los maestros que estaban trabajando eran de Chihuahua, de Jalisco, de Zacatecas, no, no sabian ni una palabra en zapoteco, ellos hablando español y los niños en zapoteco. Terminaban y les daban su certificado de sexto año. Pero tenían que ir los muchachos al internado de Zoogocho a repetir cuarto grado, porque llegaban ahi y les aplican un examen (y no aprobaban) Entonces eso fue una de las cosas que orilló a que cambiara el sistema,... esa idea de que hubiera educación indigena, porque decíamos que necesitábamos a los maestros que hablan en su lengua (zapoteca), les explicaran a nuestros hijos qué quería decir tal cosa y a la par enseñarles un español completo, ...no un español coloquial que se viene aprendiendo,... (EL, Yojovi, 1999).

Entonces, desde la escuela, ¿qué se ha hecho para desarrollar la lengua originaria, en este caso la legua zapoteca, en el ámbito escolar? En el siguiente apartado desarrollaremos este punto. En el mismo sentido, no existe la enseñanza de una segunda lengua, es decir que la segunda lengua no se tiene como lengua meta, se utiliza únicamente como medio de instrucción o como lengua puente. De esta forma, los niños indígenas al ingresar a la escuela se enfrentan con una lengua diferente que no conocen, teniendo como resultado problemas en el proceso aprendizaje al no dominar la lengua de instrucción.

Este es un tema que ha sido analizado en otros contextos en donde se tienen poblaciones bilingües o multilingües y se ha demostrado que existen ventajas cuando se utiliza la lengua materna en el proceso escolar antes de adquirir una segunda lengua. 
Sin embargo, en nuestro contexto, en las escuelas ubicadas en las comunidades indígenas, sean escuelas de educación bilingüe o escuelas de educación formal, sigue siendo un problema. ¿Cómo enfrentar esta realidad en los casos en donde se tiene esta situación o cómo llegar a un bilingüismo coordinado? ¿Cómo se puede, por un lado, resolver problemas psicopedagógicos y cognitivos en los estudiantes indígenas; y, por otro, adquirir una segunda lengua sin desvalorar la propia?

\section{2. ¿Qué piensan los hablantes sobre la lengua indígena?}

Este aspecto también es relevante porque como hemos dicho, la escuela ha sido uno de los espacios en donde se ha desprestigiado la lengua zapoteca, se le ha subestimado por carecer de una gramática, de literatura, de un alfabeto, de diccionarios, etc.; por lo tanto, se le ha considerado peyorativamente un "dialecto", un medio de comunicación de los ignorantes, de los iletrados, de los pobres, de los indígenas. Con esta idea la escuela rural mexicana educó en español desde los años veinte del siglo pasado, en consecuencia mucha gente vivió esta discriminación, esta humillación, inclusive castigos por hablar su "dialecto".

La situación que se señala originó un desplazamiento paulatino del zapoteco por el español. En este punto encontramos opiniones encontradas de padres de familia, autoridades comunitarias, maestros y líderes comunitarios. Mientras algunas personas insisten en que se siga hablando y se utilice la lengua zapoteca en el aula, otros no saben exactamente qué es lo mejor: si continuar el empleo de la lengua indígena o cambiarla por el español; alguna personas más no dudan en decidirse por el español. Quienes dicen que es importante seguir hablando la lengua zapoteca, se debe a que tienen algún antecedente con su uso o porque no han tenido conflictos o no han sufrido discriminación en los espacios donde interactúan.

Pues también, es algo que no se puede olvidar, es muy bueno porque de esa manera también hay veces, que por ejemplo, yo estuve, como le digo, estuve en la ciudad, había veces que no podíamos platicar algún secreto con otros, ¿verdad?, pues unas palabras asi, pues no, no toda la gente entiende y rápido nos hacen señas, es una ventaja. Pero a la vez también es una 
desventaja, porque eso hace que entorpezcamos un poco el hablar el español, no lo hablamos con fluidez, precisamente porque... nos dedicamos a hablar el zapoteco ... no es tan bueno seguir platicando el zapoteco (JG, Yahuio, 1999).

No obstante, esta mismas personas, conforme van reflexionando sus repuestas, ellos mismos argumentan que sería mejor hablar el español, por la experiencia que han tenido, la manera como han sido tratados en otros contextos. La misma persona de la cita anterior, por ejemplo, está a favor de la lengua indígena pero, en su reflexión se contradice, esto es muy recurrente en los hablantes de lenguas subordinadas, sobre todo de lenguas en conflicto; el entrevistado además mencionó lo siguiente:

Pues yo, de mi parte, bueno, es el punto de vista que yo tengo, ¿no? Considero que no es tan apropiado (el zapoteco) en el sentido de que, como le digo, hay veces que salimos a la ciudad y se habla bastante español, que desconocen casi la lengua materna (indígena), entonces hay mucha discriminación. Lo digo por experiencia, cuando estuve en México, no muy bien podía yo hablar el español, apenas empecé, pues, nos rechazaron, decían: "sí, oaxaco". Una discriminación muy fuerte. Entonces eso hace que uno se sienta inferior a ellos, por no poder hablar bien el español. Entonces yo considero que en nuestro caso estaría bien que todos los niños hablaran el español, para que cuando salgan a la ciudad no les sea tan problemático, ¿verdad?, hablar el español. Es la discriminación que yo he visto, que yo he vivido las veces que he salido a la ciudad. (JG, Yahuio, 1999).

Como puede constatarse, quienes se manifiestan a favor del desplazamiento de la lengua indígena, se remiten a sus experiencias, al trato que han recibido en los contextos en donde han estado, a la necesidad de comunicarse de manera eficiente con el otro, a la posibilidad de que sus hijos tengan otras oportunidades de sobrevivencia; por lo tanto, quieren aprender la lengua franca, la lengua que les permita desplazarse en otros contextos, y con ello la posibilidad de seguir estudiando y tener mejores oportunidades de vida. Esto significa que priorizan el uso del español por la 
posibilidad que les da para resolver sus problemas económicos y sociales, en cuanto que es una región que expulsa población hacia las ciudades nacionales o el extranjero. En las siguientes citas podemos leer entrelíneas tal situación:

Bueno, antes cuando yo iba a la escuela, no nos permitían hablar el zapoteco, nos prohibían hablar el zapoteco y nos castigaban si hablábamos, pero ahora veo que los maestros ya enseñan a los niños a hablar el zapoteco y ya no le dan importancia a hablar el español, y el español creo que es más necesario, y con el zapoteco creo que no nos beneficiamos en nada, por eso es así como estamos. Por eso yo pienso que es mejor que enseñen a los alumnos el español lo mejor que puedan y ojalá supieran el inglés, que lo enseñen, pero el español es lo más principal, porque ... cuando salimos a las ciudades, cuando salimos nos atoramos, ... ya salimos a otros países ya necesitamos un poco de inglés y con el zapoteco no nos beneficiamos nada,... bueno yo pienso ya con lo que sabemos es suficiente y para qué queremos aprender más del zapoteco, si ya lo sabemos pues, ya sabemos eso, ya no necesitamos saber hablar eso, por eso estamos ignorados (MC, Solaga, 1999).

No, no estoy de acuerdo porque veo mi situación como estoy ahorita y quiero que mis hijos se vayan mejorando, dominando el español, entonces ya pueden enfrentarse a cualquier persona que hable el español, así como están ahorita ni quieren saludar a una persona, por qué, porque no pueden hablar bien el español (DN, Solaga, 1999).

En el cuestionamiento que realizamos sobre la opinión de los hablantes zapotecos respecto a su lengua, emergen otros elementos como el emotivo. Al respecto refieren que es la lengua de los antepasados, que es "bonito" seguirla hablando, que no debe de desaparecer, porque sirve para establecer la comunicación interna, y que además, sobrevivirá por mucho tiempo. De igual manera insisten en que la lengua indígena tiene el mismo valor que el español, porque tiene gramática, porque se puede escribir, ya sean cartas, cuentos o la historia misma de la comunidad; y, lo más evidente, es que en 
la acción, a pesar de su contradicción que aparece en el discurso, los hablantes del zapoteco interactúan por medio de esta lengua zapoteca en diferentes contextos y cada vez de forma más abierta (Cfr. Fishman, 1970).

\subsection{La lengua de preferencia en el hogar y en la escuela}

Hay comunidades en donde la población es bilingüe incipiente, caso Yahuio, Guiloxi, Yojovi y Yaganiza, en donde la lengua cotidiana de la mayoría de las familias es el zapoteco; en otras, como Solaga, existen familias cuya lengua de interacción es el español, inclusive es la lengua que aprenden los niños a hablar en primera instancia. Lo anterior es consecuencia de las experiencias migratorias y el contacto temprano con instituciones públicas y los medios de comunicación masiva. Lo anterior en términos generales, porque existe una gran diversidad de uso de las lenguas, tanto indígena como el español. Uno de los motivos para que el español sea lengua de uso cotidiano es la exigencia de los padres de familia para que a los niños se les hable y se les enseñe en español en la escuela, mientras que en la casa se habla exclusivamente la lengua indígena. Esto, como hemos mencionado es evidente, se manifiesta en las respuestas de las entrevistas, así como en la observación: los niños aprenden la lengua indígena desde muy temprana edad. Cabe mencionar que la gran mayoría de las familias indígenas se caracteriza por ser familias ampliadas, por lo tanto, se vive y se convive con los abuelos, tíos o tías; entonces, es a través de las personas mayores como se reproduce la lengua indígena, sin olvidar los casos que hemos mencionado más arriba.

Una de las expectativas de los padres de familia es que sus niños aprendan español en la escuela, pero en la escuela (sea indígena o no indígena) el maestro no enseña español, no es la lengua meta, aunque los maestros digan lo contrario. Por lo tanto no se cumple el objetivo de los padres de familia. Tenemos algunos testimonios de padres de familia respecto a la enseñanza del español en la escuela, ellos dicen: "Sí se enseña español, porque así me dice mi hija", "Cuando pasamos por la escuela, escuchamos que el maestros habla español", "Porque todos los libros que estudian vienen en español”, "Como los niños hablan español y también muchas veces cuando nos fijamos en sus cuadernos o sus libros si los leen bien” (Yojovi, 1997). 
Por todo lo mencionado hasta aquí, se deduce que las actitudes de los sujetos involucrados en este proceso ha cambiado, no queremos decir con esto de que exista un consenso respecto al uso de la lengua indígena en el aula y la alfabetización en esta lengua, los discursos que encontramos son contrastantes, pero sí podemos decir que es otra la actitud respecto a la que se tenía antes de los años ochenta, ahora se tienen una actitud más positiva hacia la lengua zapoteca. Los discursos que encontramos en las comunidades indígenas son:

Yo creo que las dos cosas (las dos lenguas)... sería bonito que hablaran español, pero el zapoteco, por ejemplo, cuando va uno a una comunidad que hable zapoteco y si uno no entiende el zapoteco, es como si uno fuera a Los Ángeles (EUA)... no entiende inglés... dicen que la lengua materna (tiene más valor) quién sabe cuál, pero es mejor saber los dos idiomas (zapoteco/español). (MC, Solaga, 1999, tiene experiencia migratoria).

Los dos (español y zapoteco), por ejemplo el español se puede hablar con personas que no entienden el zapoteco y el zapoteco para las personas que no entienden el español. Es importante leer y escribir en zapoteco, pero lo que me interesa más a mí es que aprenda en español... el zapoteco es muy bonito, pero a la vez ellos sí necesitarían aprender más el español que el zapoteco, eso ya lo saben, y quiero que sepan más el español... (DN, Solaga, 1999).

...los dos, quiero español y quiero zapoteco ...porque hay gente que no habla español aqui, puro zapoteco ...se necesita el español para cuando salimos a otras partes, como los niños que ahora ya crecen y van a México, a Los Ángeles, necesita español, pero aquí puro zapoteco (MC, Solaga, 1999).

...es muy necesario (el español) porque cuando hay necesidad de ir a la ciudad se necesita hablar el español o pedir de comer... tiene uno que hablar el español porque allá en la ciudad no dominan el zapoteco. 
Como se puede observar, las opiniones son diversas, pero en cada una de ellas existe claridad de lo que se quiere y por qué se quiere aprender una $u$ otra lengua. La función que estas lenguas cumplen en diferentes situaciones comunicativas está presente en la argumentación que se hace al respecto, y cuando de manera específica se pregunta sobre el uso de estas lenguas en el aula, el discurso se torna más reflexivo, como se puede observar en las siguientes citas:

No, no estoy de acuerdo porque veo mi situación como estoy ahorita y quiero que mis hijos se vayan mejorando. Dominando el español, entonces ya pueden enfrentarse a cualquier persona que hable el español. Así como están las cosas ahorita, ni quieren saludar a una persona, ¿por qué?, porque no pueden hablar bien el español (MC, Solaga, 1999).

Estoy muy de acuerdo (pero) ...que nos dijeran cuál es el beneficio de aquí a diez años para un niño que pueda aprender más el español.

...cuando sea dentro de sus materias, porque siempre es más indispensable el español.

Esta situación es explicable dado que no existe claridad respecto a la función de la lengua indígena en el aula tanto en los docentes como en los padres de familia. Muchos docentes de educación indígena no han comprendido las implicaciones pedagógicas y psicológicas que tiene la lengua materna (sea indígena o no) en el proceso escolar. Por lo tanto, tampoco se ha informado a los padres de familia y a las autoridades comunitarias sobre las ventajas del uso de la lengua indígena en el proceso educativo de los niños indígenas, cuando esta es la lengua materna de la mayorías.

\section{4. El zapoteco en la escuela}

Como ya quedó demostrado, uno de los problemas agudos que se vive en las escuelas de las comunidades indígenas es la ausencia de la lengua originaria, la lengua zapoteca; en donde, inclusive se castiga al alumno que hace uso de esta lengua en el ámbito escolar. Los maestros al igual que los padres de familia consideran que si se utiliza la lengua indígena en el aula, los niños 
pueden tener problemas de aprendizaje o confundirse más, y en consecuencia tendrían repercusiones en su vida escolar futura hecho que en otros contextos y experiencias se ha demostrado que no es así (Cummings, 1987). Argumentan que el fracaso escolar es consecuencia de que no se hable el español. Por el contrario, en la escuela no se logra desarrollar la lengua originaria ni adquirir una segunda, el español. Algunos maestros han entendido que usar la lengua indígena es transferir contenidos del español a la lengua indígena. A nivel de discurso los maestros mencionan lo siguiente: a) Se usa la lengua indígena sólo cuando los niños no entienden un concepto o una palabra, b) la lengua indígena es un obstáculo en el proceso enseñanza aprendizaje, y c) la lengua indígena debe ser utilizada en el aula, "porque es bonita", "es la lengua de nuestros antepasados". Esto se reconoce como lealtad ideológica respecto a la lengua indígena, situación que no contribuye a mejorar los procesos de aprendizaje (Cfr. Ruiz, 1993). Finalmente lo que se observa en el aula es el uso frecuente del español, y como se ha dicho, la lengua indígena sólo se utiliza como lengua puente (Cfr. Muñoz, 1987). Los maestros así lo reconocen:

Pues como herramienta de trabajo podríamos decir que a diario no, no durante toda la clase sino en partes, donde a veces los niños no logran entender, $y$ he visto que sí, este, si le entienden hablándoles en su lengua (originaria) a los niños, ... hay algunas partes en donde no entienden (en español). Ahora tenemos establecido ... un horario, tengo dos horas de designadas para la lecto-escritura (en zapoteco) a la semana. (SB, Solaga, 1999).

El hecho de que la lengua de instrucción sea el español, y que se haga uso de esta lengua en todo el proceso enseñanza-aprendizaje causa serios problemas en los niños que no la dominan, ya que no existe comprensión del discurso pedagógico. Por eso algunos docentes hacen uso de la lengua indígena para romper la barrera lingüística que existe y que impide un entendimiento cabal (cfr. Lewin, 1990). Así tenemos que, la participación/interacción de los niños se reduce cuando los maestros hablan únicamente el español y nada más participan aquellos que tienen cierta competencia comunicativa en esta lengua. También se ha observado que en aquellas escuelas en donde el maestro utiliza la lengua indígena, la situación se revierte 
el proceso, hay mayor comprensión, mayor participación de los alumnos (Ruiz, 1993, Mena, Muñoz y Ruiz, 1996).

En este mismo sentido, Cummins (Cummins, 1987) nos dice que existen diversos estudios en donde se tienen experiencias del uso de la primera lengua en el proceso escolar y no se tienen problemas como los anotados más arriba, por el contrario, nos dice el autor, existen ventajas cognitivas, pedagógicas y psicológicas en los niños, cuando la instrucción se da en su lengua primaria. Además, menciona que:

...la mantención y el uso del idioma primario como medio de instrucción durante la mayor parte del día en la escuela, no tiene ningún efecto negativo en el desarrollo del segundo idioma y en muchos casos tiene efectos muy positivos (Cummins, 1987: 133).

Algunos de estos planteamientos han sido mal entendidos, $\mathrm{y}$ lo que se observa en la práctica docente es una explicación en lengua indígena de las instrucciones de ejercicios o tareas académicas a realizar. En otros, se da un proceso de transferencia de los contenidos programáticos a la lengua indígena, y con esto se cree que se está utilizando dicha lengua como lengua de instrucción.

Utilizar la lengua indígena en el ámbito escolar es algo más complejo, se requiere de un conocimiento más amplio respecto a la lengua que se enseña, se necesita conocer a los niños que se atienden, las necesidades de éstos, el contexto en donde se desenvuelven, etc.; en resumen, se requiere de un saber interdisciplinario (Brown, 1994) para poder hacer realidad este principio del uso de la lengua materna en el proceso escolar. Sin embargo, en las escuelas de la zona de estudio, lo único que se ha logrado es, a partir de la imposición del español como segunda lengua, una actitud negativa respecto a la primera lengua, aunque si bien es cierto hoy día esta imposición no está relacionada con castigos ni sanciones como en otros tiempos.

Los maestros que trabajan en las comunidades indígenas, de manera general, al igual que los padres de familia, consideran que el uso de la lengua indígena en el aula es un retroceso con respecto a la "civilización". Además, se argumenta que esta lengua, el español, es la que les va ser útil en su vida; pero, no se piensa en el problema psicopedagógico que tiene el alumno frente al docente que solo usa el español en el proceso escolar. Otro argumento que se escucha 
repetidamente es el siguiente: "El maestro debe enseñar el español, porque el zapoteco ya lo saben (los niños), eso lo aprenden en la casa..." (YA-1996).

Otra pregunta que está latente en los padres de familia y los maestros es: ¿Qué va pasar con los niños cuando terminen sus estudios de educación primaria si se les enseña en lengua indígena? En este aspecto existe una gran preocupación en cuanto al uso de la lengua originaria en el aula, pues los niños al término de la educación primaria tendrán que salir de la comunidad para continuar sus estudios o trabajar; por lo tanto, se exige la enseñanza del español. No obstante, encontramos dos situaciones; por un lado, no se ha entendido el por qué se plantea el uso de la lengua indígena en el aula, ni la función pedagógica y psicológica que esta cumple en el aula, cuando esta es la primera lengua. Y por el otro, el hecho de que no se enseñe el español como lengua meta. El español como segunda lengua, lo aprenden los niños a través de la interacción y del contacto cotidiano con otros medios.

Para poder superar el desconocimiento de la lengua de instrucción, en muchas ocasiones los maestros castigaban física o psicológicamente al alumno o los multaban por utilizar su lengua nativa en el ámbito escolar, con la finalidad de aprender el español. En otros casos piden a los padres de familia introducir a sus hijos en el aprendizaje del español, con resultados muy negativos, como acertadamente lo menciona Cummins (1987), ya que en este caso la mayoría de los padres de familia no tienen un dominio pleno del español, en consecuencia no existe la posibilidad de usar el español en el ámbito familiar, y cuando se realiza, no se obtiene el objetivo deseado. Muchos padres de familia son bilingües incipientes, por lo tanto no hay posibilidades de ayuda para el aprendizaje del español como segunda lengua.

La actitud respecto a la lengua indígena es otro factor que ha incidido en cuanto a la función de la lengua en el aula. Históricamente la población indígena ha sufrido una discriminación no sólo como sujeto, sino también como un portador de una cultura y una lengua diferentes. En este sentido, existe una actitud negativa en relación a la lengua indígena, la cual en algunos contextos indígenas ha sido desplazada, en otros se ha reducido su funcionalidad en el ámbito familiar o comunitario. En otros casos, la situación es más alentadora, debido a que existen espacios en donde la lengua indígena está 
recuperando su función comunicativa, como la escuela, en donde se hay un proceso de revaloración, producto de un proceso muy largo.

Al respecto se tienen algunas experiencias muy interesantes en algunas escuelas, en donde se ha propiciado el desarrollo de la lengua materna en los primeros grados de educación primaria, con resultados muy favorables (Cfr. Mena y Ruiz, 1996; Mena y Ruiz, 1996a; Mena, y Ruiz, 1997). En términos de alfabetización en lengua indígena se tiene, por ejemplo, una experiencia interesante en dos comunidades de la Sierra Juárez, en las cuales se ha demostrado lo que se conoce como proceso de transferencia lingüística, en donde, después de que los niños se alfabetizaron en la lengua indígena, fue para ellos relativamente más sencillo adquirir el código escrito de la segunda lengua (Cfr. Mena, Muñoz y Ruiz, 2000). Pero, es lamentable decir que este proceso de alfabetización en lengua indígena es cuestionado por muchos maestros, pues se piensa que son dos procesos diferentes de adquisición de la lengua escrita y que por lo tanto les significaría doble tiempo hora-clase. En consecuencia, se niegan llevar a cabo este proceso.

Una experiencia más se refiere a un grupo de alumnos de tercer grado de educación primaria, quienes en el primer ciclo escolar se alfabetizaron en lengua indígena y se comprobó que su nivel de comprensión de lectura fue más alta que la de aquellos alumnos que no tuvieron este proceso. Estas son algunas experiencias en donde se utiliza la lengua materna como lengua de instrucción. Pero existen muchos espacios escolares en donde está ausente dicha lengua. En este sentido Cummins anota lo siguiente:

Hay dos razones principales por las cuales el idioma primario de los niños puede promoverse en la escuela sin interferir con el desarrollo del idioma predominante: 1) los niños tienen muchas oportunidades de escuchar el idioma predominante en su medio ambiente, por ejemplo, en la radio y en la televisión; y 2) el desarrollo de conceptos lingüisticos desempeña un papel principal en el desarrollo intelectual y académico de los niños y una vez que estos conceptos se han desarrollado en el idioma primario pueden transferirse fácilmente al idioma predominante (Cummins, 1987: 137). 
Aunque si bien cierto que es otro el contexto al cual hacemos referencia, también lo es que este proceso de contacto con diferentes medios de comunicación se está dando de manera paulatina en las comunidades indígenas, y el porcentaje de personas en contacto con los medios de comunicación masiva es cada vez más alto.

\subsection{Alfabetización en lengua indígena}

A nivel aula ¿qué se ha hecho en cuanto a la enseñanza de la lengua originaria? Existen algunas experiencias en la Sierra Juárez, aunque no todas registradas, porque difícilmente se les puede dar seguimiento, debido a que los profesores no fácilmente permiten el acceso a las aulas, pues las consideran un espacio privado. A pesar de ello, tenemos evidencias de estas experiencias en Yovego, Solaga, Yaganiza, Yojovi, Guiloxi, Zoochina y Yahuio, en donde los docentes nos han dado la oportunidad de observar sus prácticas escolares. En estos espacios se han apreciado procesos incipientes de alfabetización en lengua indígena o el uso de la lengua indígena en el proceso escolar. Aquí hay que tener claridad respecto al uso de la lengua indígena en el aula, ya que no la utiliza para desarrollar contenidos étnicos o comunitarios o el proceso de adquisición del conocimiento, lo que se hace es transferir contenidos del programa escolar a través de la lengua indígena o hacer breves explicaciones en esta lengua.

A pesar de todo, las experiencias de algunos maestros de educación indígena son importantes, en tanto que han hecho el mayor esfuerzo por lograr una práctica docente diferente. La experiencia en la Escuela Primaria de Yovego, la clase se desarrolló en lengua indígena durante todo el primer año escolar (primer ciclo escolar), realizando diferentes actividades con distintos contenidos. No sólo se alfabetizó en lengua indígena, sino abarcó las otras áreas programáticas: matemáticas, historia, ciencias naturales, civismo, etc. Se observó de igual forma que el docente generó sus propios cantos y rondas en lengua indígena, los cuales le sirvieron para motivar a sus alumnos, en otros casos tradujo cantos y rondas del español al zapoteco, que también es motivo de reconocimiento.

Aunque, el hecho de utilizar la lengua indígena en el proceso escolar, no implica que los alumnos vayan a aprender los contenidos de manera automática. Se hace necesario también recurrir a otro tipo de metodologías de enseñanza, en donde no sólo se mejore 
la interacción maestro alumno, sino también se propicie un mejor desarrollo de las capacidades cognitivas, en donde no únicamente se use la repetición, memorización, asimilación, recepción de conocimientos (Cf. Freire, 1984) sino una educación que propicie la reflexión, la crítica, así como actitudes y valores en torno del aprendizaje de la lengua materna y la segunda lengua (Cf. Cassany et al.). ${ }^{15}$

En el seguimiento que realizamos en la experiencia de Yovego y Yaganiza, se aplicaron tests para conocer el desarrollo de habilidades lingüísticas de los niños. La evaluación mostró un mayor desarrollo de habilidades en los niños de Yovego respecto a la experiencia de Yaganiza. Lo anterior se debe a que la experiencia en la primera escuela fue básicamente en lengua indígena, mientras que en la segunda, la clase se desarrolló en español y la lengua indígena se utilizó como lengua puente (Cf. Mena, Muñoz y Ruiz, 2000). Como se menciona arriba la experiencia en Yovego se dio durante el primer ciclo ( $1^{\mathrm{o}}$ y $2^{\circ}$ grado de educación primaria), en segundo grado se consolidó el proceso de alfabetización e inició con el español oral. Aquí surge otro problema, el desconocimiento de una propuesta metodológica de enseñanza de segundas lenguas. Pero a pesar de ello, la experiencia de Yovego fue interesante ya que se inició con diálogos y expresiones orales a partir de un tema elegido por el maestro o por los alumnos.

Desafortunadamente, las pocas experiencias que existen no tienen seguimiento, no son registradas ni evaluadas. Cuando se tiene la oportunidad de sistematizar la experiencia, como el caso de Yovego, se truncan y no existen posibilidades de conocer sus resultados a más largo plazo. El seguimiento que se le dio a esta experiencia quedó en el primer ciclo. Existía la intención del docente de realizar esta experiencia durante los seis grados de educación primaria; por cuestiones fuera del control del maestro, que tienen que ver con los propios compañeros docentes, con la comunidad, con el apoyo de las autoridades educativas, esta experiencia no tuvo continuidad. El caso de Yaganiza, Solaga o Yojovi, fueron

15 Siguiendo con algunos de los postulados de algunas experiencias en contextos similares de bilingüismo, se ha llegado a la conclusión de las ventajas cognitivas y académicas que se obtienen si se parte en la primera lengua del niño (Cummins, 1987). 
experiencias con prácticas de uso o enseñanza de la lengua indígena pero de forma menos sistemática.

Una cuestión relevante en esta experiencia es el hecho de la transferencia lingüística, que consiste en que los niños aprenden con alguna facilidad el código escrito de una segunda lengua cuando son alfabetizados en su lengua materna primero, en este caso, la lengua zapoteca. El docente pudo comprobar esta afirmación a partir de su propio trabajo, pudo observar a través del tiempo que sus alumnos iniciaban a leer en español sin muchos problemas. Este proceso de transferencia de habilidades lingüísticas es poco aceptada por los docentes. En sus testimonios se nota esta posición “... es trabajar doble, primero les voy a enseñar a leer y escribir en lengua indígena, y cuándo les enseño en español, el programa de estudios me pide que lo haga en español" (FG, Solaga, 1999).

Otro problema que se presenta es la falta de apoyo didáctico, materiales, textos, etc.; sin embargo esto no es ningún obstáculo cuando se está consciente de lo que se quiere hacer en el campo educativo. Para el maestro de Yovego, él elaboró en el proceso los materiales didácticos que iba requiriendo, así como los cantos, rondas, cuentos, etc., de acuerdo con los objetivos de clase.

El objetivo general del maestro fue la alfabetización, sin descuidar las otras asignaturas, retomando los objetivos generales del Plan y Programa de Educación Primaria, fue elaborando su plan de actividades y su clase la desarrolló en lengua indígena. Esta experiencia fue única, porque la enseñanza de la lengua indígena o el uso de ésta como lengua de instrucción en las otras escuelas se dio de manera diferente. En la escuela de Guiloxi, por ejemplo, la maestra atendía a los alumnos del grupo multigrado a una hora determinada dando la clase de "lengua indígena", que consistía básicamente enseñar a leer y escribir en zapoteco. La misma situación se repitió en Solaga pero con alumnos de sexto grado, en Yojovi con los alumnos de quinto grado y de manera muy elemental con los alumnos de primer grado. Estas algunas experiencias que se tienen de manera aislada y con poco continuidad y seguimiento.

\subsection{Por qué se valora positivamente el español}

La mayoría de los entrevistados en las comunidades indígenas consideradas en este trabajo, valoran positivamente el aprendizaje del español porque tiene funciones prácticas. Hasta los 
años noventa la discriminación hacia la lengua indígena y quienes la hablaban era muy fuerte; por lo tanto, la gente pedía aprender el español y renegaba su lengua originaria. Hoy en día esta actitud ha cambiado, aunque siguen persistiendo la necesidad de aprender el español por diversas razones, por ejemplo, el hecho de que los niños tienen que continuar sus estudios, o emigrar a otros contextos para buscar trabajo o inclusive el desempeñar un cargo municipal en la comunidad, por ello es prioritario aprender el español.

Bueno es que cuando nosotros salimos de nuestro pueblo, vamos a una ciudad y ahí vemos que la gente habla bien el español, por eso queremos igualar a esa gente, imitar a esa gente, lamentablemente no lo podemos hacer, no podemos expresar bien el español (YA, 1996).

Le digo que he oído que el inglés puede favorecer algo a un niño o una niña, puede encontrar un trabajo, puede hablar el inglés y fácil puede encontrar un trabajo en una ciudad, pero hablando el zapoteco, qué va a conseguir ahí (MC Solaga, 1999).

Existe pleno convencimiento de la necesidad de una lengua franca, en este caso el español, que se utiliza para la comunicación con gente que no domina la lengua zapoteca o la variante dialectal del lugar, así como con aquellos que son hispanohablantes. La comunicación entre los sujetos es imprescindible, ya que existe la necesidad de interactuar, de intercambiar productos o fuerza de trabajo, por ello es necesario aprender el español para poder desplazarse a otros contextos. En ese sentido, los entrevistados ven el aprendizaje del español como algo importante, y dicen:

Que se aprenda hablar el español pues, sí, es importante porque es lo que se habla en México, yo considero de que lo que se habla es lo que se tiene que hablar y aprender muy bien para que se tenga más comunicación, porque de otra manera no podríamos comunicarnos. Por ejemplo, en algunos pueblos rurales marginados, anteriormente todavía, ahora ya se ve diferente. Anteriormente en este pueblo nadie podía hablar español, entonces veían alguna persona que hablaba el español se echaban 
a correr o se escondian, en algunos otros pueblos todavía sucede eso verdad, no sé exactamente qué pueblos, pero se oye de que pues no saben español y mejor se esconden y luego nosotros si queremos ir por ejemplo por ahí por los Mixes, por aquí el Rincón todavía nos entendemos un poco, pero cómo vamos a platicar, cómo vamos a comunicarnos si ellos usan un dialecto y nosotros otro, entonces no nos podríamos comunicar, y conociendo únicamente el español sí nos podemos comunicar, en ese aspecto sí es muy necesario que se aprenda el español (JG. Yahuio, 1999).

Es muy necesario, porque muchas veces salimos fuera de la comunidad y a otras partes y es necesario saber español para tener comunicación verdad, para poder hacer preguntas a las personas, porque si hablo en zapoteco no me van a entender (Yojovi, 1999).

Enseñar una segunda lengua es otro problema en las escuelas de las comunidades indígenas. Aquí cabría preguntarnos: ¿El maestro enseña una segunda lengua? En primera instancia, podríamos decir que sí enseña una segunda lengua, en este caso el español, ya que es la lengua que utiliza el docente durante todo el proceso enseñanzaaprendizaje. Esta es precisamente la respuesta que dan los padres de familia al hacerles dicha pregunta. Se cree que con el hecho de que el maestro hable español durante toda la clase se está enseñando esta lengua; pero como hemos mencionado, no existe tal objetivo, el español no se tiene como lengua meta, se usa como lengua de instrucción con resultados poco favorables. Al término de ciclo escolar o de la educación primaria, uno de los grandes problemas que se presenta es que los alumnos no comprenden o no entienden lo que se les explica o lo que leen.

Esta situación crea una falsa expectativa tanto en los maestros como en los padres de familia, porque ni se ayuda a desarrollar la lengua materna del niño (lengua indígena), ni se enseña una segunda lengua (el español). Podemos asegurar que en ninguna escuela en la región o en el estado se conoce una propuesta metodológica para aprender español como segunda lengua. Los alumnos aprenden de manera indirecta esta lengua, a través de la lectura, del discurso del maestro, con sus compañeros, del contacto con otras personas que 
hablan español o por el contacto que se tiene con los medios masivos de comunicación como la radio o la televisión, en donde se cuenta con estos medios.

El uso del español en el aula de manera general, impide la comprensión del discurso pedagógico; así como la interacción activa en el aula. De igual forma ocurre con los textos, en el momento en que se realiza la lectura individual o coral, en muchas ocasiones existen problemas semánticos debido a que los textos contienen palabras desconocidas para los niños, y si pensamos en niños de primero y segundo grados de educación primaria, el problema aún es mayor.

Por ello, es indispensable desarrollar el lenguaje del niño partiendo de su lengua materna, para posteriormente acceder a la segunda lengua. El objetivo final debería consistir en el hecho de que el niño se convierta en un sujeto con competencia comunicativa en ambas lenguas. Pero, para lograr este tipo de bilingüismo, es necesario tomar en cuenta lo que señala Cummins:

Los padres deben darse cuenta de que el bilingüismo no se desarrolla automáticamente por el solo hecho de que el niño está expuesto a dos idiomas. El desarrollo completo de ambos idiomas en un ambiente en el que el idioma propio es otro que el predominante, requiere de los padres planear deliberadamente formas de promover el idioma primario tanto dentro como fuera de la casa (Cummins, 1987: 137).

Por lo expuesto podemos decir que el bilingüismo no causa ningún problema cuando se tiene claridad en cuanto la función de cada lengua y que existen ventajas académicas e intelectuales, cuando se canaliza bien este tipo de enseñanza. Es una necesidad el aprender de manera eficiente la cada una de estas lenguas, dado que la población se enfrenta a diferentes situaciones comunicativas, el siguiente testimonio nos lo demuestra:

Para nosotros, en la comunidad, pues el zapoteco, pero si va uno a la ciudad de Oaxaca, pues el español, yo pienso que son importante los dos. Porque se nos dificulta, si salimos a una ciudad y no sabemos el español, no puede uno salir, si uno es de esta comunidad y no sabemos el zapoteco también se dificulta. Hay paisanos que no pueden hablar el 
zapoteco aún siendo de aquí, para mí que el zapoteco y el español... Aunque mi dialecto es mejor, porque lo puedo platicar con mis paisanos o con cualquier persona de la región, se puede uno expresarse mejor con el zapoteco (AC, Yaganiza, 2000).

Lo ideal es que la escuela ayude a que los niños desarrollen un bilingüismo cordinado para poder ser competentes en las diferentes situaciones comunicativas. Sin embargo, las experiencias nos indican que estamos lejos de lograr este objetivo.

\section{Conclusiones}

La lengua zapoteca como un elemento de cohesión y de identificación, ha sufrido diversos embates, en consecuencia está en una situación frágil, en una situación de lucha constante de revaloración y revitalización, de recuperar espacios comunicativos importantes. Para algunas lenguas indígenas se habla de un proceso de desplazamiento o de extinción, para el caso del zapoteco en las comunidades de estudio esto no es así, por el contrario hay una proceso de revitalización, gracias a los diferentes factores socioculturales que hemos mencionado. La escuela por ejemplo, es un espacio que se tiene que pensar de otra manera, con un modelo educativo diferente.

Uno de los grandes objetivos de nuestras sociedades actuales es ser más humanos, objetivo tal vez un tanto utópico. La tendencia de una educación intercultural es buscar el respeto a la diversidad, la tolerancia y la internalización de valores que lleven a lograr estos propósitos. En este sentido, el respeto a la lengua y revaloración de la cultura en el proceso escolar debe ser fundamental.

Para que la escuela juegue un papel crucial, existe, por un lado, la exigencia de formar nuevos cuadros de profesionistas que atiendan este sector de la población. Que tengan una visión menos fragmentada de la educación, con una idea de educación más igualitaria. Por el otro lado, la obligación de que la sociedad no indígena aprenda a respetar y a valorar las culturas minoritarias con las cuales convive cotidianamente. En este sentido, existe la necesidad de una reeducación de toda la sociedad, tanto a nivel local, estatal, nacional e internacional, de tal forma que podamos 
entender, comprender, valorar y respetar las diferencias culturales y lingüísticas que prevalecen en nuestras sociedades.

Uno de los problemas graves en el ámbito educativo, y de manera especial, en aquellas comunidades donde trabajan maestros de educación indígena intercultural, que se supone tienen cierta formación para poder llevar a cabo una educación bilingüe e intercultural, es no entender el papel que puede desempeñar la lengua materna de los niños en el proceso escolar. Existen muy pocas escuelas en donde se está poniendo en práctica el uso de la lengua indígena como lengua de instrucción. Desafortunadamente en nuestro contexto oaxaqueño no existe ninguna experiencia en donde se pueda hacer una investigación de manera longitudinal y demostrar lo expuesto en este trabajo. Solo se tienen experiencias aisladas en los primeros grados, con resultados muy favorables, pero que no se conocen con amplitud.

Se le ha apostado mucho a la construcción de alfabetos prácticos para resolver los problemas de la educación indígena. Se ha invertido en recursos humanos, económicos y mucho tiempo en esta actividad y el modelo de educación indígena no se ha hecho realidad. Después de aproximadamente 20 años de haberse generado un alfabeto práctico para la lengua zapoteca, no se observan cambios o avances sustanciales, creemos que el alfabeto práctico no es el punto medular en la Educación Intercultural Bilingüe, existen otros factores que han quedado sin resolverse como: la formación docente, propuestas metodológicas de alfabetización bilingüe, métodos para la enseñanza de segundas lenguas, mayor difusión de las lenguas indígenas, el uso y las funciones de las lenguas indígenas y el español, etcétera.

$\mathrm{Al}$ respecto debemos de reconocer que la lengua indígena está en una situación de lengua subordinada, en el sentido de que ocupa espacios reducidos de comunicación. Se usa en el hogar y en la comunidad, en la escuela de alguna forma empieza a utilizarse. Pero no puede aún sustituir al español en procesos comunicativos más "formales", en el proceso enseñanza-aprendizaje, no logra convertirse en lengua de instrucción, aunque ya existen textos en lengua indígena para la educación básica indígena, pero hay maestros que se resisten a utilizar estos materiales. Aunque, también creemos que no es únicamente a través de la escuela como se puede revalorar la lengua zapoteca y las lenguas indígenas en general, como se ha mencionado, sino se requiere de otros espacios, como los medios 
masivos de comunicación y de otros factores socioculturales como los mencionados; además de hacer realidad las reformas constitucionales y la ley de los derechos lingüísticos.

El bilingüismo es una necesidad, como se demuestra en los testimonios de los sujetos investigados, se tiene claridad respecto a la importancia de una lengua u otra, dependiendo de las situaciones y espacios comunicativos. Por ello se exige que se enseñe el español por ser considerada la lengua franca, la lengua que se utilizará en contextos donde solo se hable esta lengua y la lengua zapoteca porque es la lengua originaria de nuestros pueblos y es útil en nuestros contextos.

\section{Bibliografía}

AGUIRRE BELTRÁN, Gonzalo (1967). Regiones de Refugio. Instituto Indigenista Interamericano, México.

BARTH, Fredrik (1976). Los grupos étnicos y sus fronteras. Fondo de Cultura Económica, México.

BRICE HEATH, Shirley (1986). La politica del lenguaje en México: de la Colonia a la Nación.Edit. INI, México.

BROWN, Douglas H. (1994). Principles of Lenguage, Learning and Teaching. Prentice Hall Regents, Englewood Cliffs.

CASSANY, Daniel, Marta Luna y Gloria Sanz (1994). Enseñar lengua. Grao, Barcelona.

CASTELLANOS M., Javier (1999). Yell chhia lhen xtilla. Zanhe xbab Sa, A.C. Segunda edición, Oaxaca, México.

CID-SIERRA (1996). GWZIO. Revista Cultural, Zapoteca, Mixe, Chinanteco. Oaxaca, México, enero-junio.

COULON, Alain (1995). Etnometodología y Educación. Edit. Paidós, México.

CUCHE, Denys (1999). La noción de cultura en las ciencias sociales. Edit. Nueva Visión, Buenos Aires.

CUMMINS, Jim (1987). "Conservando la lengua madre en los niños que hablan un idioma diferente al idioma predominante: algunos conceptos erróneos", en Colección Pedagógica Universitaria, $\mathrm{N}^{\mathrm{o}} 15$. Universidad Veracruzana, México, pp. 133-138. 
DE LA FUENTE, Julio (1949). Anales del Instituto Nacional de Antropología e Historia. México.

DE LA FUENTE, Julio (1989). Educación, antropología y desarrollo de la comunidad. Edit. INI-CNCA, México.

DIETZ, Gunther (2001). Multiculturalismo, Interculturalidad y Educación. Granada, España.

FRIERE, Paulo (1984). Pedagogía del oprimido, Siglo XXI, México.

GEERTZ, C. (1992). La interpretación de las culturas, Barcelona, Gedisa.

GIMÉNEZ, Gilberto (1999). "La importancia estratégica de los estudios culturales en el campo de las ciencias sociales", en Rossana Reguillo Cruz y Raúl Fuentes Navarro (coords.): Pensar las Ciencias Sociales hoy, ITE$\mathrm{SO}$, México.

GIMÉNEZ, Gilberto (2000). “Territorio, cultura e identidades: La región sociocultural", en: Rocío Rosales Ortega (coord.) Globalización y regiones en México, UNAM-FCPyS/Porrúa, México.

GIMÉNEZ, Gilberto (2001). "Identidades étnicas: estado de la cuestión", en Leticia Reyna (coord.) Los retos de la etnicidad en los estados-nación del siglo XXI, CIESAS-INI-PORRÚA, México.

GIMÉNEZ, Gilberto (2000b). "Identidades en Globalización”, Revista Espiral, Sep-Dic., Volumen VII, Universidad de Guadalajara, México.

GUMPERZ, John J. (1982). Discurse strategies. Cambridge: Cambridge University Press. USA.

INEA, (1991). Bzoj dilla xhon. INEA, Libro y Cuaderno de ejercicios, México.

INEGI (1997). Anuario Estadístico del Estado de Oaxaca. Edición, INEGI, México.

INEGI. Censo General de Población y Vivienda, INEGI, México, 2000.

LEWIN, Pedro (1990). "Conflicto sociocultural y conciencia lingüística en Oaxaca", en: Barabas, Alicia y Miguel Bartolomé (Coord.). Etnicismo y pluralismo cultural: la dinámica étnica en Oaxaca. Edit. CNCA, México.

Ley General de Derechos Lingüísticos de los Pueblos indígenas. Comisión de Asuntos Indígenas y Comisión de Educación y Servicios Educativos. Cámara de Diputados, LVIII Legislatura, México, marzo de 2003. 
MENA, Patricia y Arturo Ruiz L. (1997). "La formación docente: una de las necesidades prioritarias en el contexto de la educación indígena", en: $L a$ educación indígena hoy. IEEPO-Huaxyácac, México, pp. 170-182.

MENA, Patricia y Arturo Ruiz (1996). "Práctica docente y actitudes de los maestros de Oaxaca hacia la educación indígena", en: Reportes de Investigación educativa. Formación y actualización de maestros. Edit. SEP, México, 1996.

MENA, Patricia y Arturo Ruiz (1996a). "Actitudes lingüísticas e ideologías educativas en comunidades indígenas de Oaxaca", en: H. Muñoz y Pedro Lewin (Coords.). El significado de la diversidad lingüística y cultural. UAM-I-INAH-Oaxaca, México.

MENA, Patricia, Héctor Muñoz y Arturo Ruiz (2000). Identidad, Lenguaje $y$ Enseñanza en escuelas bilingües indigenas de Oaxaca (2a . Edición) Edit. UPN-UABJO, México.

MOLINA CRUZ, Mario (1995). El arco iris atrapado, CID-Sierra, Oaxaca, México.

MOLINA CRUZ, Mario (Coord.) (1998). Yi'kube (Fuego nuevo). Taller de lengua y tradición zapoteca de Yalalag, Oaxaca, México.

MUÑOZ, Héctor (Ed) (1987). Funciones sociales y conciencia del lenguaje. Universidad Veracruzana, México.

MUÑOZ, Héctor et al., (1995). Bene Xhon. Guía para alfabetización bilingüe y libro de trabajo, CID-Sierra, Oaxaca, México,

MUÑOZ, Héctor y Pedro Lewin (1996). El significado de la diversidad lingüistica y cultural. UAM-I-INAH, México.

RENDÓN, Juan José y Bárbara Cifuentes (1983). "Algunas observaciones acerca de la función de la lengua en una comunidad lingüística zapoteca", en: Nueva Antropología. Vol. 1, No 22, México.

RUIZ LÓPEZ, Arturo (1993). Educación Indígena: del discurso a la práctica docente. UABJO, México.

SEP-DGEI, (1993). El bilingüismo en la práctica docente indígena (Antología) SEP, México.

THOMPSON, Jhon (1998). Ideología y cultura moderna. Teoría crítica social en la era de la comunicación de masas, UAM-X, México.

Recebido para publicação em maio de 2018.

Aceito para publicação em junho de 2018. 